\title{
Numerical modelling approach for the management of seasonal influenced river channel entrance
}

\author{
Michael T.W. Tay*, S.B. Mitchell, J. Chen, J. Williams \\ School of Civil Engineering and Surveying, University of Portsmouth, \\ Portland Street, Portsmouth P01 3AH, UK
}

\section{Introduction}

The processes that occur in and around river channel entrances are a vast and very complex subject that has been studied by countless researchers over a long period of time (Pruszak and Szmytkiewicz 2005) (Samaras and Koutitas 2014). Changes in the morphologies of river channel entrances, known as delta systems, become more pronounced over the last century as a result of sea-level change, changes in fluvial processes, and urbanisation (Zbigniew, et al. 2005).

Today, more than three billion people live in the coastal zone (Hinrichsen 1998). With the increasing influence of human activity along the coastal lines including urbanisation, there has been an increase in surface water runoff, causing an increase in river flow and sediment influx towards river channel entrances. About $80 \%$ of people who live in coastal regions are vulnerable to flooding, of whom $38 \%$ are located in Asia, mostly in South East Asia (Veerbeek 2007). Hence, a better understanding of the morphology of river channel entrances is crucial to improve coastal resource planning and management.

The configuration of a river channel entrance strongly depends on the incident of wave energy on the adjacent shoreline (Wright and Coleman 1972). For that reason, the 
change in morphology as a function of waves and river discharges should be considered in terms of the formation of a river channel entrance discharge system (Wright and Coleman 1973). The morphology of a river channel entrance is also affected by tidal currents and waves, in addition to the sources from ocean energy which include various types of currents, storm surge, and climate change causing eustatic rises in sea level (Galloway 1975)..(Stanley and Warne 1994)..(Wong, et al. 2014) (Bonaldo, et al. 2015). Additionally, most of the major river channel entrances in Southeast Asia were formed during the Holocene, leading to the mobilisation of large quantities of sediment (Woodroffe, et al. 2006).

Previous modelling studies have shown that the prevailing climate of the South China Sea is governed by the North East (NE) and South West (SW) Monsoons, resulting in a local wind speed of around 10-14m/s. (ICZM Task Force 1998) (Razak, et al. 2012) (S. M. Abdullah 1992) (Husain, Yaakob and Saad 1993) . The North East Monsoon season lasts from December to March, and the South East Monsoon season lasts from June to October, with the intervening time termed as transition period (Outskirtoutrich.org n.d.). Xue (2012) had proposed a similar directional shift in the coastal current from North East to South West during the monsoon period in the South China Sea. South East Asia, surrounded by South China Sea, also known as wetting region where frequent tropical storms and typhoons occur. (Santini and Paola 2015).

Most of the river channel entrances of Sabah, Malaysia are known to cause major flooding due to the restriction of water flow, causing backwater effects (M. K. Abdullah 2012). Advanced and sophisticated techniques are required to measure and predict the physical changes that occur to the morphologies of the river channel entrances in 
Sabah, especially Petagas river channel entrance. A numerical model is applied for its cost effectiveness advantage in predicting the outcome of a management system.

Waves plays an important role in sedimentation and coastal morphology much so at the entrance of a river channel. (Amoudry 2008) (Chiang and Hsiao 2011) (Valsamidis, et al. 2013). The overall patterns in the month-to-month wave directions are related to the dominant directions of the monsoon winds (Mangor 2007).

Tides play an important role in circulation. The tidal regime at the site of interest is mixed, mainly diurnal with one tidal cycle per day and $F=2$ (Lisitzin 1974), based on a constituent analysis of tidal harmonics by the Kota Kinabalu Port Authority (Malaysian Metrological Department 2010).

Sedimentation is one of the most common problems affecting the management of a river channel entrance (Jayappa and Narayana 2009) (Mashriqui 2003) (Nylen and Ramel 2011) (Robakiewicz 2010) (Nelson, et al. 2013). This complex phenomenon occurs throughout Malaysia under hydraulic conditions as the velocities are low, causing sand and silt to be deposited on the river bed (Department of Irrigation and Drainage, Malaysia 2001). The study of sedimentation dynamic behaviour in relation to temporal pattern need to be carried out with prolonged and reliable data collection (Roy, et al. 2012). An understanding of sedimentation requires the proper description of the hydrodynamic processes of tides, river flow, and the morphology of the bed (Department of Irrigation and Drainage, Malaysia 2001). Using hydrological data obtained from the Petagas River, it has been shown that the incident wave direction during the SW monsoon is the principal factor that affects the morphology of the river 
channel entrance. Sedimentation at the Petagas channel entrance is known to exacerbate flooding in the Moyong River. According to the local authorities, the navigational conditions of the Petagas river have worsened over the last few years.

The shallow bathymetry of the Petagas river channel entrance had caused more sedimentation due to effect from increased bed friction, which further contributing to flow deceleration and lateral expansion of the river channel entrance (Wright, 1977).

Erosion and sedimentation in river channel entrances can be conducted by means of techniques involving a combination of bed surveys, Acoustic Doppler Current Profiler (ADCP) measurements, and numerical modelling. A good number of such studies were conducted, including those undertaken in the Mekong River Delta in Cambodia, which discharges into the South China Sea (United Nations 1969) (Kocar and Scott 2012) (Xue, et al, 2012) (Schmitt and Albers 2014). Numerical modelling was applied in this case to predict the outcomes of different management solutions (Wang, et al. 2014) (Stark, et al. 2016) or even the future shapes of the river channel entrances, due to its cost effectiveness advantages- cheaper and faster than physical modelling.

In recognition of this, a numerical model is proposed in this paper that includes the effects of different monsoon phenomena, in relation to its influence of varying tides and fluvial discharge on river channel entrance dynamics. In addition, the effectiveness of a set of management solution during monsoon periods are analysed, which is the primary focus of this research. The overall objective of this paper is to provide an approach through numerical modelling in solving monsoon influenced river channel entrance problems. 
The paper is structured as an approach to numerical modelling where section 2 describes the overall topography necessary to cover Petagas River channel entrance as well as introducing a set of management solution. Section 3 describes the necessary modelling approach in building a mesoscale model which elaborates on model platform, data utilisation and model setup. Section 4 shows the outcome of the well represented reductionist model in terms of wave condition, then the outcome from the calibration of the hydrodynamic model is shown and further describes the effectiveness of the coupled model. The result of the proposed management solution aiming at minimising sedimentation behaviour in relation to inter-annual climate variations in the monsoon seasons is also shown and along with it demonstrates the effectiveness of the reduced complexity model approach. At the final section of the paper, conclusions are drawn, including the importance of numerical modelling in solving future river channel entrance problems and its ability to provide suggestions for policy-makers in managing river channel entrance that is subjected to monsoon influences. 


\section{Topography of the Petagas River Channel Entrance}

\subsection{Overview of Existing Condition}

Located in Sabah, Malaysia (Formerly known as North Borneo), the Petagas river serves as one of the major discharges of the Moyong catchment, which covers an area of $297 \mathrm{~km}^{2}$ (DID 2011). With the expansion of the urban centre of Kota Kinabalu into the Moyong floodplain, a transition in terms of land use is ongoing, from rural development and cultivation of rice paddies to intensive urban development, causing immense changes in the characteristics of the rivers located in the Moyong Catchment, especially the Petagas river (DBKK 2011). Apart from being one of the largest and most important catchments in terms of economic development, the Moyong basin receives a rainfall intensity of up to $400 \mathrm{~mm}$ per day, one of the highest in Malaysia (DID 2011). At its channel entrance, the Petagas river is located immediately to the south of Kota Kinabalu International Airport (KKIA), a major international transport hub. The channel connects and discharges into the South China Sea by a southwestoriented channel, which is about $50 \mathrm{~m}$ wide at this location.

The Petagas river channel entrance is located on the West Coast of Sabah near the town of Putatan, a few kilometres to the south of Kota Kinabalu City, Malaysia (Figure 1). The river discharges fresh water into the South China Sea. 


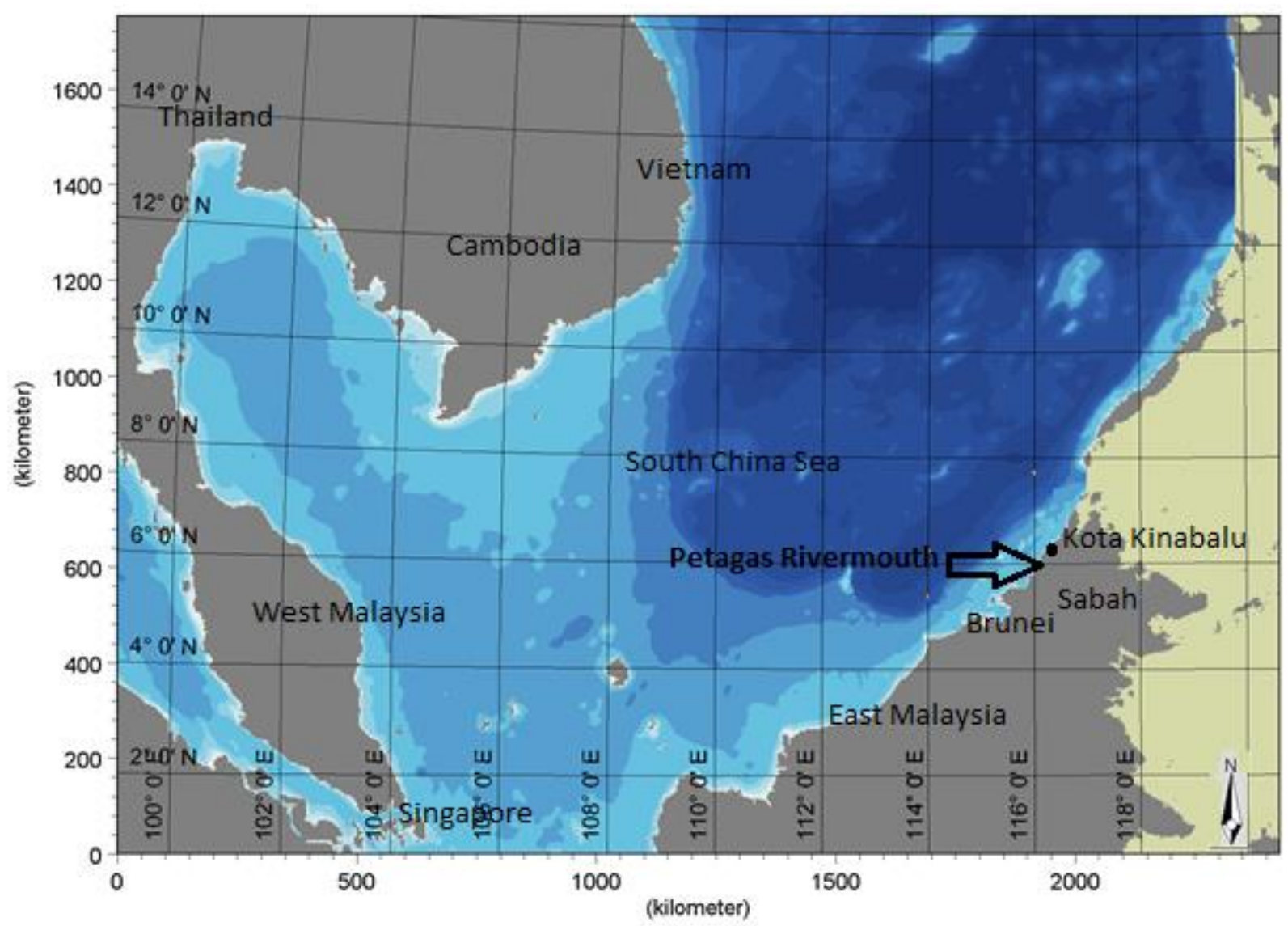

Figure 1: A regional map showing the location of the Petagas River channel entrance 


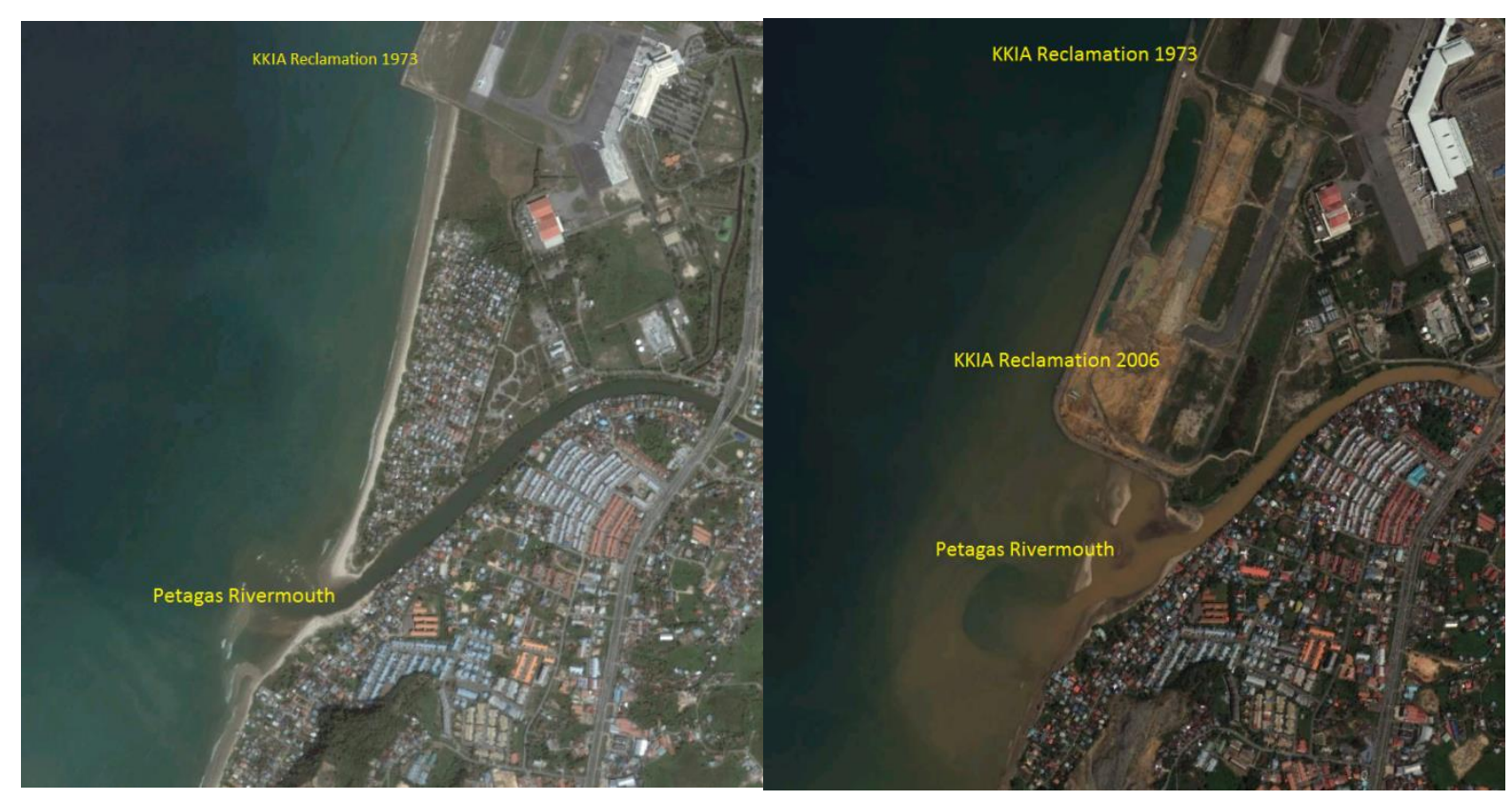

Figure 2: Satellite Imagery of the Vicinity of the site (a) from 2002 before reclamation and (b) from 2010 after the reclamation of 2006.

The bathymetry of the river channel entrance is highly variable due to ongoing sedimentation. Figure $2 \mathrm{~b}$ demonstrates that continuous reclamation since 1973 has led to a very shallow river channel entrance with a sand bar stretching approximately $200 \mathrm{~m}$ southward from the runway reclamation. This reclamation was done for the extension of the airport runway to accommodate bigger aircraft. Fig. 2(b) also shows the discolouration of the water in the channel as a result of a highly suspended sediment load. 
The river channel entrance is connected to the catchment upstream by a single channel. The dynamic morphology of the channel entrance is largely affected by the inter-annual variations in climate caused by the Northeast (NE) and Southwest (SW) monsoons. Recent development in the catchment has caused an increase in discharge and sediment supply (Department of Irrigation and Drainage 2011). The prevailing ocean current is the same as the prevailing wind direction in the South China Sea at this point. The tides are mixed with a mean tidal range of $1.8 \mathrm{~m}$, with diurnal dominance (Lisitzin 1974), and their effects are restricted to the coastal zone. Some tidal flats have formed in the vicinity of the river channel entrance. The fresh water discharge varies in the range $20 \mathrm{~m}^{3} / \mathrm{s}$ during inter monsoon season to $40 \mathrm{~m}^{3} / \mathrm{s}$ during monsoon seasons according to flow data measured from the river. 


\subsection{Management Solution}

As previously discussed, the main objective of this paper is to validate a numerical model of sedimentation in the Petagas river channel entrance by assessing the effectiveness of introducing a set of proposed improvement works, aiming at minimising the dynamic sedimentation behaviour caused by inter-annual climate variations in the monsoon seasons.

The major requirement for local policy makers is a management solution that allows a sufficient discharge through the entrance throughout the two monsoon seasons; which will solve the upstream flooding issue. The proposed management solution should allow continuous access through the river channel entrance for both large and small scales of fishing crafts, thereby helping to sustain the local economy.

Coastal structures commonly lead to detrimental coastal impacts in the vicinity. Designated improvement works with minimum impacts on the coastal environment preferred in this setting 


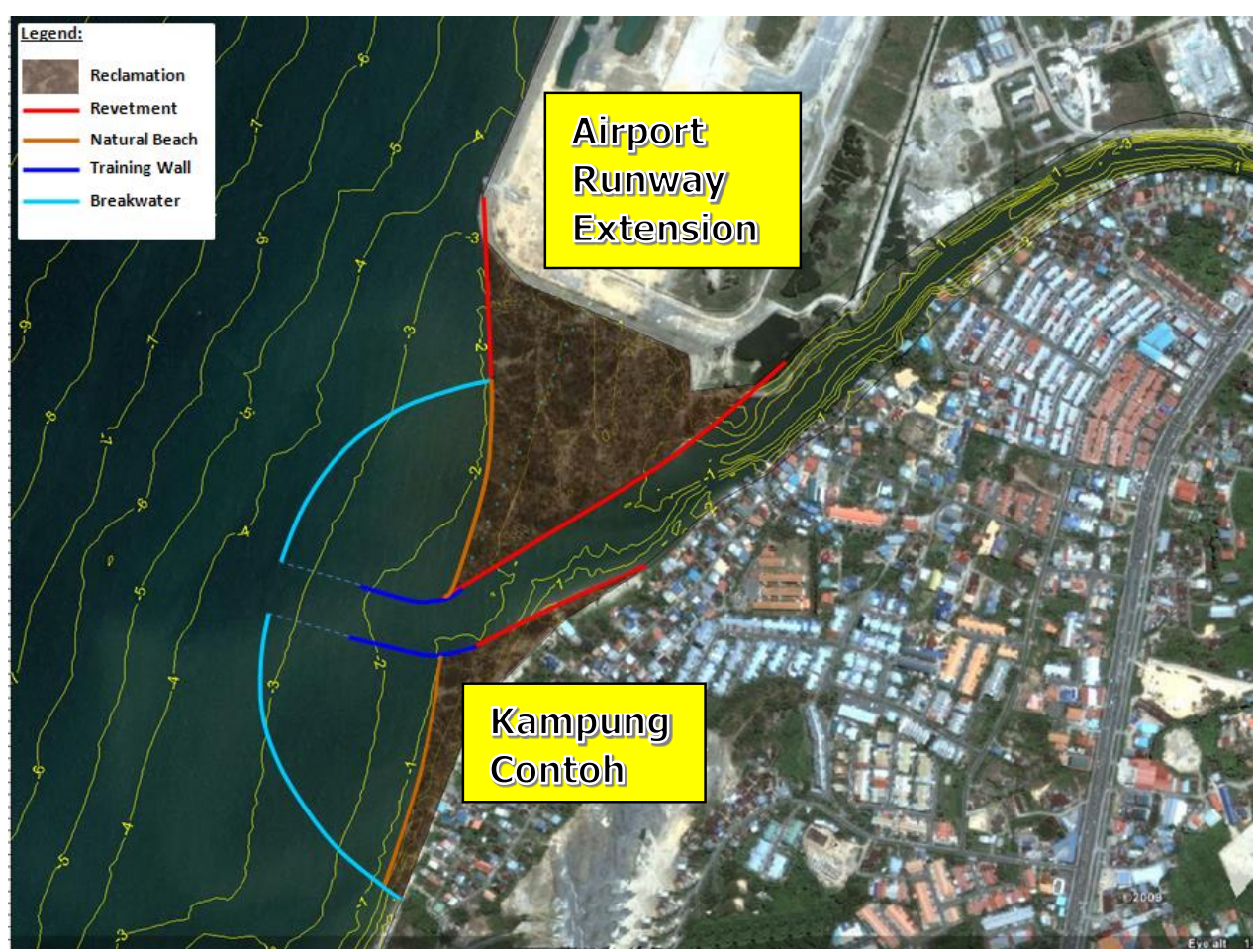

Figure 3 : Protection measures proposed for Petagas river channel entrance by maintaining the existing river channel alignment with breakwaters

The layout shown in Figure 3 involves the training of the river channel entrance to follow the natural alignment of the access channel. The training requires revetments to be constructed along both river banks and around the existing sand spit and seawards. Reclamations are being carried out to extend the airport to the south and also along the western side of Kampung Contoh. Breakwaters are to be constructed and the main channel will be dredged. 


\section{Methodology}

Well represented numerical model must archive an ability to make quantitative predictions of morphological change at a scale that is sufficient to cater for long term strategic coastal management (French and Burningham 2009). This scale is known as mesoscale where as a whole can be quantify between time horizons versus spatial dimensions in the order of 101 to 102 years and 101 to $102 \mathrm{~km}$ respectively. With this scale, modelling forecast should be robust enough for policy makers to make decision (J. French, et al. 2016). The dynamic nature of mesoscale coastal evolution can accurately be represented by deploying 2 types of model that is Reductionist and reduced complexity model - RCM (Liang, et al. 2015), where reductionist model is better in including a board spectrum of scale which include all processes that can potentially effect the system's evolution but it is more limited in predicting future changes (Woodroffe and Murray-Wallace 2012). Reduced complexity model is more suited in geomorphology terms where it focuses more on the particular area of interest that are crucial to describe a situation (Walkden and Hall 2011) which is well suited for the assessment of potential coastal management solution (Walkden, et al. 2015). Previous studies has been carried out that successfully integrate this two modelling approach into one overarching framework (Nichollas, et al. 2012). Accordingly, This study adopt the approach of reductionist model in correctly representing the wave and hydrodynamic modelling in combination with reduced complexity modelling in representing sediment dynamics and management solution prediction. Therefore, it will accurately include the open coast, river channel entrance, inner shelf and their interaction in a system as a whole, including all sediment dynamics and the respond of the system when potential management measures is in place. 
With that in mind, a numerical approach based on the finite volume method was proposed in this investigation and the commercial software MIKE was used to represent the effectiveness of improvements to the river channel entrance. The MIKE suite of software was developed by the Danish Hydraulics Institute (DHI) and is widely used for numerical simulations of currents and waves in coastal areas. MIKE21, in which the "21" denotes two-dimensional (2D) flow calculations in 1 layer of (vertically homogeneous) fluids, is applied effectively in the cases of flows, waves and sediments in rivers, estuaries, coasts and oceans. MIKE21 is constantly undergoing development to enhance user experience as well as on going improvements, including rapid processing (Aackermann, et al. 2012) and a better user interface. The model is applied in this study to investigate the dynamics of the Petagas river channel entrance.

The modelling is started by generating waves in a spatial condition, followed by hydrodynamic analysis. Sediment is taken into account on the verified model which includes the before and after effect of a proposed management measures. Description of the extended model is further described in this section.

Firstly, waves are generated in the model using MIKE21 SW spectral wave module. The model is a 2D spectral wind-wave model that includes the effects of growth, decay and transformation of wind-generated waves and swells from offshore to the coastal zone. For this purpose, reliable information on the wave climate at the site in question is important; enabling the accurate prediction of the sediment deposition processes (Soomere, et al. 2008).

In Cartesian co-ordinates, the conservation equation for MIKE21 SW is: 


$$
\frac{\partial N}{\partial t}+\nabla \cdot(\vec{v} N)=\frac{s}{\sigma}
$$

Where $N(\vec{x}, \sigma, \theta, t)$ is the action density, $\vec{x}(x, y)$ represent Cartesian co-ordinates, $\vec{v}\left(c_{x}, c_{y}, c_{\sigma}, c_{\theta}\right)$ is the propagation velocity of wavegroups in the four-dimensional phase space $\vec{x}, \sigma, \theta$, and $S$ is the source term for the energy balance equation. The symbol $\nabla$ represents a 4D differential operator in the $\vec{x}, \sigma, \theta-$ space. Overall $\theta$ represents wave direction and $\sigma$ is relative angular frequency $\left(\sigma=2 \pi f_{r}\right)$.

The four characteristic propagation velocities are influenced by the following:

$$
\vec{v}\left(c_{x}, c_{y}\right)=\frac{d \vec{x}}{d t}=\vec{c}_{g}+\vec{U}
$$

Where, $c_{x}, c_{y}, c_{\sigma}, c_{\theta}$ are the wavegroup propagation velocities and:

$$
\begin{gathered}
c_{\sigma}=\frac{d \sigma}{d t}=\frac{\partial \sigma}{\partial d}=\left[\frac{\partial d}{\partial t}+\vec{U} \cdot \nabla_{\bar{x}} d\right]-c_{g} \vec{k} \cdot \frac{\partial \vec{U}}{\partial s} \\
c_{\theta}=\frac{d \theta}{d t}=-\frac{1}{k}\left[\frac{\partial \sigma}{\partial d} \frac{\partial d}{\partial m}+\vec{k} \cdot \frac{\partial \vec{U}}{\partial m}\right]
\end{gathered}
$$

$\mathbf{S}$ is a space co-ordinate in the direction of the wave $\theta, m$ is a co-ordinate perpendicular to $\mathrm{s}$, and $\nabla_{\bar{x}}$ is $2 \mathrm{D}$ differential operator in the $\vec{x}$-space (DHI Water \& Environment 2007a) .

The hydrodynamic module MIKE 21 HD simulates variations in water level and flow rates in response to a variety of forcing functions in lakes, estuaries and coastal 
regions. The module functions by applying the Alternating Direction Implicit (ADI) techniques to combine the equations of mass and momentum in the space-time domain, and solves the equation mainly by using a cell-centred finite volume method (DHI Water \& Environment c 2007). The equations for conservation of mass and momentum are integrated over the vertical plane ((5)), the description of flow ((6)) and variations in water level ((7)):

$$
\begin{gathered}
\frac{\partial \xi}{\partial t}+\frac{\partial \mathrm{p}}{\partial x}+\frac{\partial \mathrm{q}}{\partial y}=\frac{\partial \mathrm{d}}{\partial t} \\
\frac{\partial \mathrm{p}}{\partial t}+\frac{\partial}{\partial x}\left(\frac{p^{2}}{h}\right)+\frac{\partial}{\partial y}\left(\frac{p q}{h}\right)+g h \frac{\partial \xi}{\partial x}+\frac{g p \sqrt{p^{2}+q^{2}}}{C^{2} \cdot h^{2}}- \\
\frac{1}{\rho_{w}}\left[\frac{\partial}{\partial_{x}}\left(h \tau_{x x}\right)+\frac{\partial}{\partial y}\left(h \tau_{x y}\right)\right]-\Omega_{q}-f V V_{x}+ \\
\frac{h}{\rho_{w}} \frac{\partial}{\partial x}\left(p_{a}\right)=0 \\
\frac{\partial \mathrm{p}}{\partial t}+\frac{\partial}{\partial x}\left(\frac{p^{2}}{h}\right)+\frac{\partial}{\partial y}\left(\frac{p q}{h}\right)+g h \frac{\partial \xi}{\partial x}+\frac{g p \sqrt{p^{2}+q^{2}}}{C^{2} \cdot h^{2}}- \\
\frac{1}{\rho_{w}}\left[\frac{\partial}{\partial_{x}}\left(h \tau_{x x}\right)+\frac{\partial}{\partial y}\left(h \tau_{x y}\right)\right]-\Omega_{q}-f V V_{x}+ \\
\frac{h}{\rho_{w}} \frac{\partial}{\partial_{x}}\left(p_{a}\right)=0
\end{gathered}
$$

$\xi(x, y, t)$ represents the surface elevation, $h(x, y, t)$ is the water depth, $d(x, y, t)$ is the time-varying water depth, $\mathrm{p}, \mathrm{q}(\mathrm{x}, \mathrm{y}, \mathrm{t})$ are the flux densities in the $\mathrm{x}$ - and $\mathrm{y}$-directions $\left(\mathrm{m}^{3} / \mathrm{s} / \mathrm{m}\right)=(\mathrm{uh}, \mathrm{vh}) ;(\mathrm{u}, \mathrm{v})$ are the depth-averaged velocities in the $\mathrm{x}$ - and $\mathrm{y}$-directions, $\mathrm{C}(\mathrm{x}, \mathrm{y})$ represents the Chezy coefficient of bed resistance $\left(\mathrm{m}^{1 / 2} / \mathrm{s}\right)$ (DHI Water \& Environment d 2009).

The model was run for both the tide-only (without waves) cases and the tide together cases with the dominant NE and SW monsoon wave conditions. Field measurements 
were obtained using ADCP and were collected for the calibration and verification of the hydrodynamic models, including tidal water level variation and current speed.

Sedimentation is predicted by using a combination of ocean and river energy. The detailed modelling of waves and tide- and wave-driven currents is performed under MIKE $21 \mathrm{HD}$.

Sedimentation occurs as the result of the decrease in the velocity of the current, causing insufficient supports to the transportation of the particles. Prevention of siltation is crucial in maintaining the river channel entrance. In this study, sediment transportation is investigated using the MIKE 21 Mud Transport (MT) module in view of the predominance of fine particles at this location.

The governing equation for sediment deposition is:

$$
S_{D}=W_{s} C_{b} P_{d}
$$

$W_{s}$ is the settling velocity, $C_{b}$ represents the near bed concentration, and $P_{d}$ is the probability of deposition (Krone 1962). 


\subsection{Data Utilisation}

\subsubsection{Bathymetric Survey Data}

A bathymetric survey of the area was carried out, and an ASC II file was produced by using Borneo Rectified Skew Orthomorphic (BRSO) map projection, with the datum being equivalent to local chart datum (CD). Cross-shore profiles extending seawards from MLLW (mean low low water) and a long shore profile were obtained, to verify the accuracy of the collected data. An example of the processed bathymetric survey data is shown in Figure 4 for the purpose of setting up the model.

\subsubsection{Tides}

For tidal behaviour, a 15-minute interval of water levels were obtained from the KMS global tide model and nearby tidal stations. The KMS global tide model of the Danish Geodata Agency is a database that captures the major diurnal and semidiurnal tidal constituents. Information on tidal variations at nearby stations were obtained from tide tables provided by the UK Admiralty and the Royal Malaysian Navy.

\subsubsection{Wind Conditions}

To include the regional effects of wind on the local current conditions, nowcast wind data from the Global Forecast System (GFS) were obtained. The Global Forecast System (GFS) is a global numerical weather forecast model run by NOAA (National Oceanic and Atmospheric Administration, USA).

Wind speed and direction measured at Kota Kinabalu International Airport during the survey period were obtained from the Malaysian Meteorological Department, in order to assess the effect of local wind conditions on the site. 
Time series of hindcast offshore wind data (speed and direction) were purchased from the GROW wind wave model - see next section.

\subsubsection{Wave Conditions}

Hindcast offshore wave and wind data at $6.875^{\circ} \mathrm{N}$ and $115^{\circ} \mathrm{E}$ were obtained from the GROW global wind wave model for the period 1970-2009 and were transformed to the site using MIKE21 SW, allowing the determination of both the nearshore directional wave statistics and the longshore variations in wave energy. GROW (Global Reanalysis of Ocean Waves) is a global deep water wave model with a resolution of $0.625^{\circ}$ in latitude by $1.25^{\circ}$ in longitude. The model is based on the reanalysis of marine surface wind field and assimilation to wave measurements. The model was developed by Oceanweather Inc (GROW n.d.).

\subsubsection{Acoustic Doppler Current Profiler}

Acoustic Doppler Current Profiler (ADCP) is an instrument to measure current speed and direction over an entire water column. ADCP measures data non-intrusively with unmatched efficiency compared to other equipment (Kim and Mustle 2012). The main component ADCP measures are the flow velocity, flow direction and the water level over flow depths and transects. A comprehensive range of scientific and practical analyses related to ocean and river hydrodynamic are supported with the data obtained from the instrument, as shown in (Dinehart and J. 2005); (Guerrero, et al. 2014). ADCP data investigation and collection is conducted by validating nonhomogeneous numerical flow solutions (Harding, et al. 2016). For model validation, comparison with simulated results were carried out with the data obtained from an $A D C P$ at the site in this study. The ADCP was deployed in three locations (river channel, 
deep water and shallow water) between 7th May 2010 at 11:00 to 21st May 2010 at 13:30 for each locations. 


\subsection{Model Setup}

\subsubsection{Wave behaviour in relation to local conditions}

The local nearshore wave conditions applied in the models were based on the results of numerical modelling using MIKE 21 SW due to the unavailability of long term wave measurement in the vicinity of the site. In order to obtain comprehensive results, varied model resolution was carried out throughout the model domain, with a higher resolution in the nearshore area in the vicinity of the river channel entrance. The representation of the bathymetry in a flexible mesh allows progressive horizontal refinement of the parameters (e.g., the water depths) from offshore to nearshore areas. The bathymetry of the modelled area is fairly complex due to the higher incidence of offshore shoals and fringing coral reefs which should be resolved accurately, at least to the accuracy of the bathymetric charts available for the area. The unstructured meshes for the models were constructed using bathymetric data obtained from the British Admiralty Sea Charts with reference to Mean Sea Level, MSL $(+1.23 \mathrm{~m}$ above mean sea level at this site), as well as other available survey data.

The numerical wave transformation was carried out in two stages, in order to obtain a high spatial resolution for nearshore sediment transport modelling at an acceptable computational cost. The bathymetry and mesh used for the transformation of waves from offshore in the first stage are shown in Figure 4.

Hindcast offshore wave and wind data at $6.875^{\circ} \mathrm{N}$ and $115^{\circ} \mathrm{E}$ were obtained from the GROW wind wave model - refer to section 3.1.4 . For regional wind data input, GFS nowcast wind data were used - refer to section 3.1.3. 


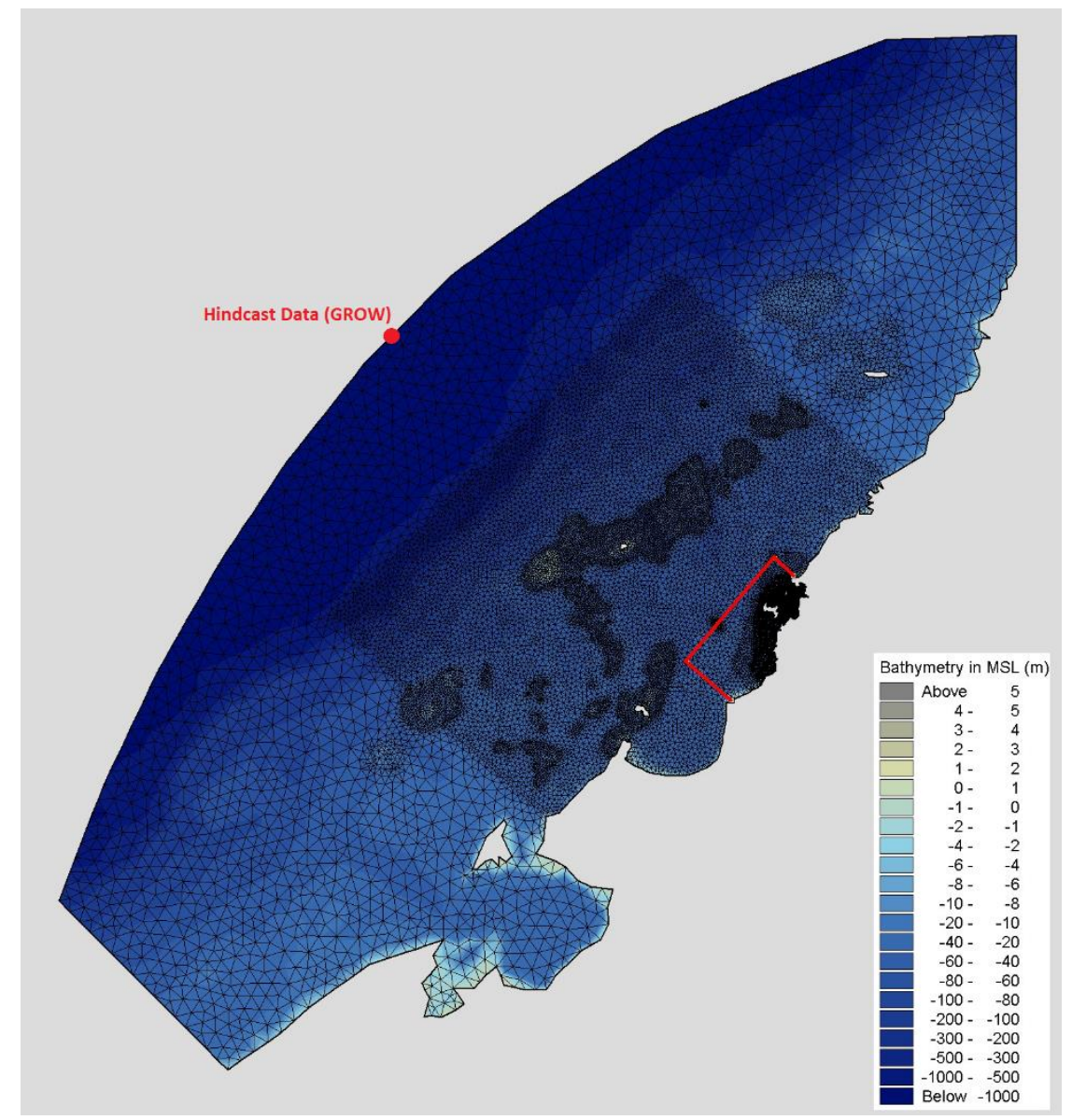

Figure 4: Unstructured mesh used for transformation of waves from offshore. The mesh resolution increases in relation to the incidence of bathymetric features that affect the transformation ( $\mathbf{e}_{\text {. }} \mathrm{g}_{\text {"r }}$ islands and shoals) and is likewise increased in the vicinity of the marina. Location of hindcast data from GROW.

For nearshore wave modelling, a higher spatial resolution was required and a local and more detailed model was used to transform the waves from deeper water ( $40 \mathrm{~m}$ MSL) to the nearshore (second stage). The mesh density gradually increased as it approached the river channel entrance, in order to avoid excessive images distortion caused by changes in bathymetry (Martins Silva, Öchsner and Adams 2011). 


\subsubsection{Model Grid and Hydrodynamics}

The hydrodynamic modelling involved two stages. In the first stage, a regional hydrodynamic model was used to describe the effect of regional scale factors on the nearshore current conditions at the river channel entrance. The model was defined using a combination of specific regional information.

In the second stage, a local model of the river channel entrance with the immediate area were used in order to provide detailed information on the current conditions. Flexible mesh was applied in the model to represent the bathymetry, which allowed a higher resolution at the river channel entrance. The model functions by obtaining input from various data sources and was driven mainly by boundary conditions generated by the regional model, as well as the effects of wind and river discharges.

A larger regional model is required to capture the governing current flows, due to the complex current field at the offsite of the West Coast of Sabah. This is mainly caused by the interaction of the tidal waves in the South China Sea with the regional currents driven by regional wind and local pressure fields. This model is able to capture the larger-scale of the flow characteristics, including parts of South China Sea, which are essential in reflecting the conditions at the boundary of the local model.

The basic hydrodynamic model is based on known tidal elevations along four (4) open boundaries of the regional grid, (north, south and west boundaries, see Figure 5a). The 2D regional model setup was established with boundary conditions depending on the water levels derived from the KMS global tide model, which is a database representing the major diurnal and semidiurnal tidal constituents. 

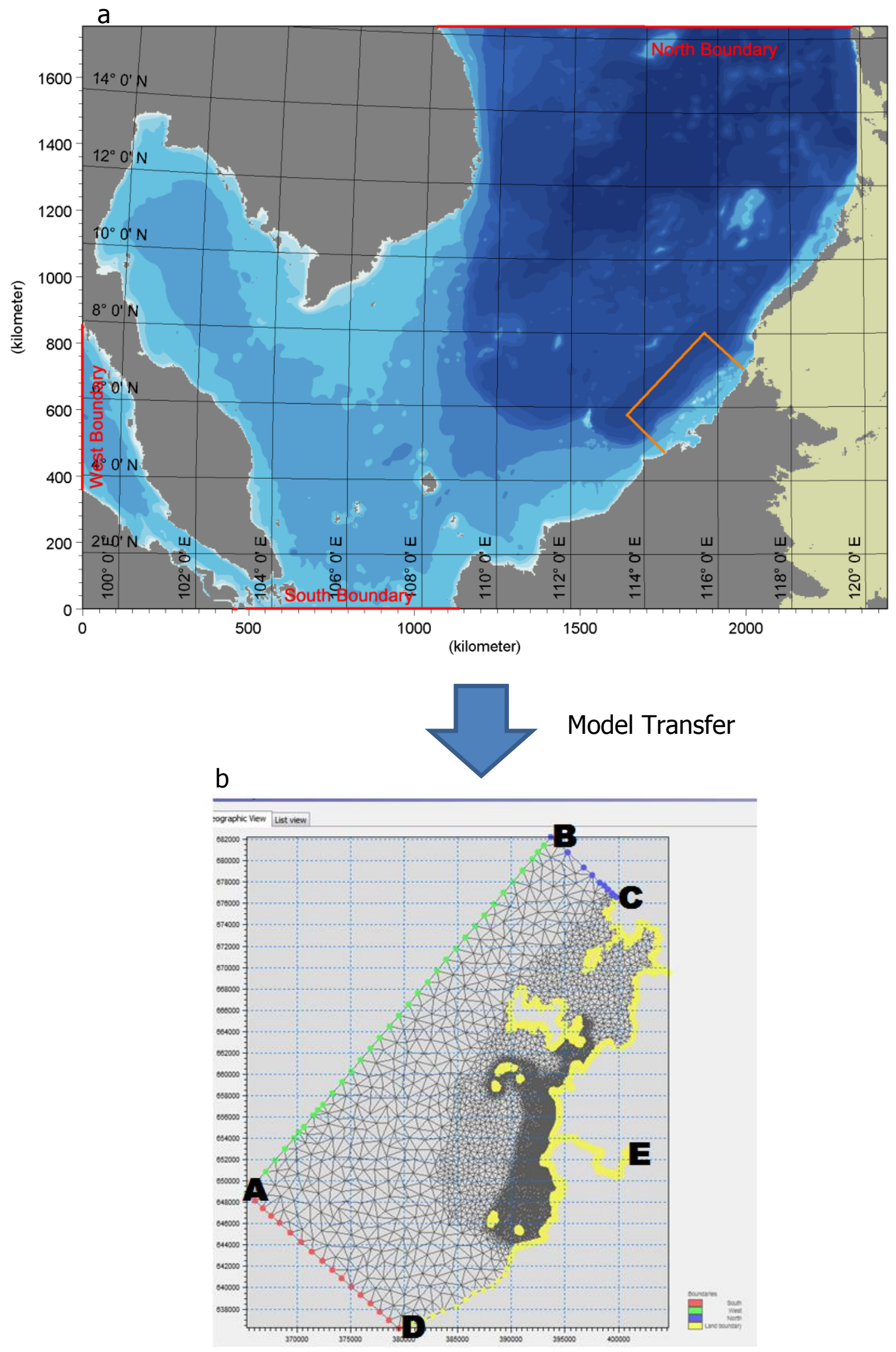

Figure 5: Boundary Condition for (a) Regional Model then transferred to (b) Local Model. 
As for the local model, this mesh was created with a higher resolution towards the shore and the river channel entrance, with element sizes of less than $100 \mathrm{~m}^{2}$ in the river, at the river channel entrance and along the adjacent coastline. The model was driven by boundary conditions along the lines $\mathrm{D}-\mathrm{A}, \mathrm{A}-\mathrm{B}$, and $\mathrm{B}-\mathrm{C}$ of the tidal and wind induced fluxes obtained from the regional model (see Figure $5 b$ ), in order for further calibration and validation against local measured water levels and current measurements. The boundary BC represents the land boundary. Point E represents the input from the river discharge.

The local model was applied to produce instantaneous tidal, wind- and wave-driven current patterns for the existing condition as well as for the proposed improvement works during typical NE and SW monsoon periods for the flood and ebb tide. 


\subsubsection{Sedimentation}

A sediment dynamics model was set up (MIKE 21 MT) for sediment discharges, in order to assess the impacts of the improvement works, as well as the existing cases. The model included the transportation of fine sediments (mud), deposition, resuspension and erosion, with considering of the variation of hydrodynamic conditions, tide and seasons.

Attention is drown towards cohesive sediment because mud distributes more landwards and sand more seawards (Zhou, et al. 2015). The examples include cases in Wash bay, UK (Amos 1995), Jade bay, Germany (Frienrichs 2014). On that account, the subsequent improvement works should subjected mainly to mud with secondary attention to fine sand. Although MT is used predominately to analyse cohesive sediment, the model also examine non-cohesive fine suspended sediment (DHI Water and Environment 2007) which is applicable in this case.

A coupled model with incorporation from the outputs from hydrodynamic and spectral waves was applied, in order to represent an accurate sedimentation. Simulation is done with varying monsoon seasons. The accuracy of a sediment dynamics model is highly dependent on the attached complex hydrodynamic model, which is controlled by natural processes such as waves on a large scale (Lesourd, et al. 2003); (Deloffre, et al. 2006). Hence, the wave field which is the key input parameter is generated from the wave simulation and the verified hydrodynamic module.

Early transport models commonly uses general mean grain size to represent the whole spectrum of sediment information (Engelund and Hansen 1967). However, this method is unable to predict the changes in grain size and it is also likely to under 
predict the transport rate of the finer fractions (Wilcock and Kenworthy 2002), in which the analysis is needed in this case. From the grab sample tests results, the sediment is categorised as loam with almost equal distribution between 3 fractions. These include course (fines), medium (fines) and fine (fines) with mean sediment size of $0.08 \mathrm{~mm}, 0.04 \mathrm{~mm}$ and $0.007 \mathrm{~mm}$ respectively, according to the distribution curve. The average settling velocity for each of the fraction is then determined using Stoke's Law formula. The sediment source has been determined with the average load of $25 \mathrm{mg} / \mathrm{l}$ based on data obtained from the Alam Sekitar Malaysia (ASMA), a local authority administrating the Moyong river station upstream.

Sedimentation was represented over a full neap-spring tidal cycle for NE and SW monsoon periods in the evaluation of the management measures, which are further described in the following sections. 


\section{Results}

\subsection{Wave Conditions}

Apart from river discharge, wave climate is one of the important factor for sedimentation and coastal morphology. Examples of wave transformations for typical NE and SW monsoon conditions are shown in Figure 6a and Figure 6c, with detailed wave fields near the river channel entrance shown in Figure $6 \mathrm{~b}$ and Figure $6 \mathrm{~d}$.

From the figures, most of the offshore waves are originated from the north-north-east (NNE) and the west-south-west (WSW) (associated with the monsoon seasons). In general, the largest waves approach from a north easterly direction. Wave refraction causes the waves to become increasingly perpendicular to the depth contours in shallow water as the waves propagate towards the shoreline. The wave heights reduce as its approach the coastline due to the effects of wave breaking and bottom friction. Figure 6a clearly illustrates the effects of diffraction, refraction and sheltering for offshore waves from northerly and north-easterly directions, resulting in lesser wave penetration into nearshore areas. In addition, the NE monsoon refraction and sheltering change the predominant wave direction from NNE to westerly towards the shoreline, resulting in a direct exposure to severe waves. A minor shoaling effect is also observed during both monsoons. 
a

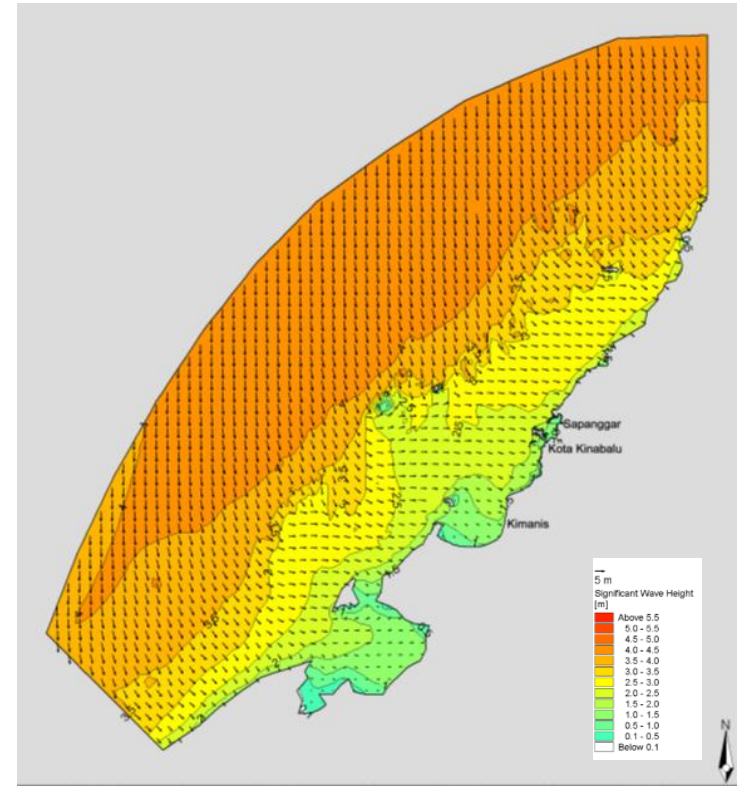

c

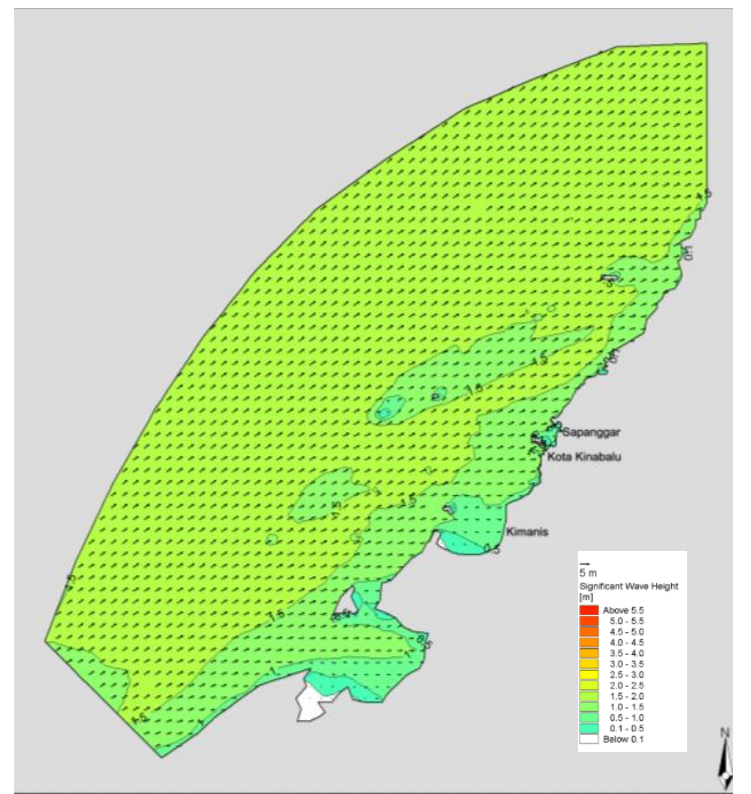

b

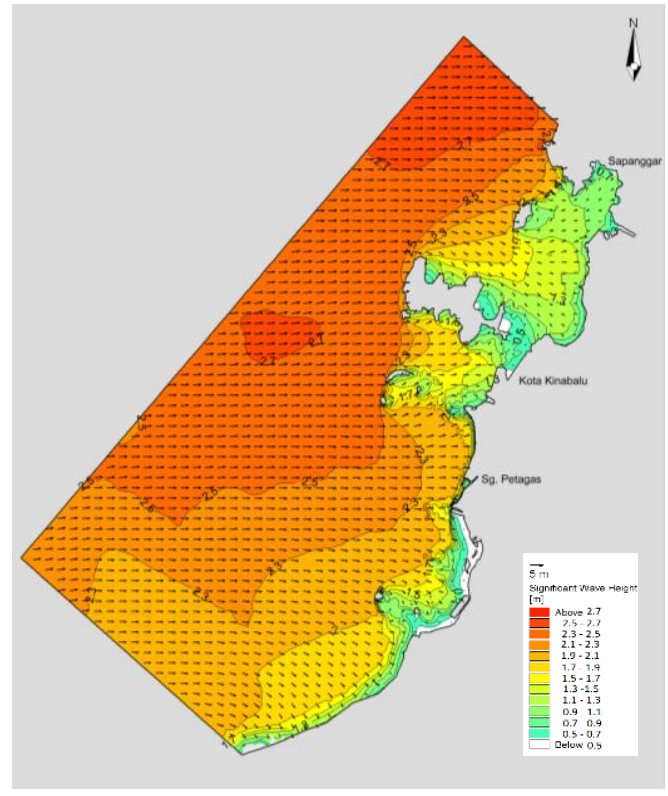

d

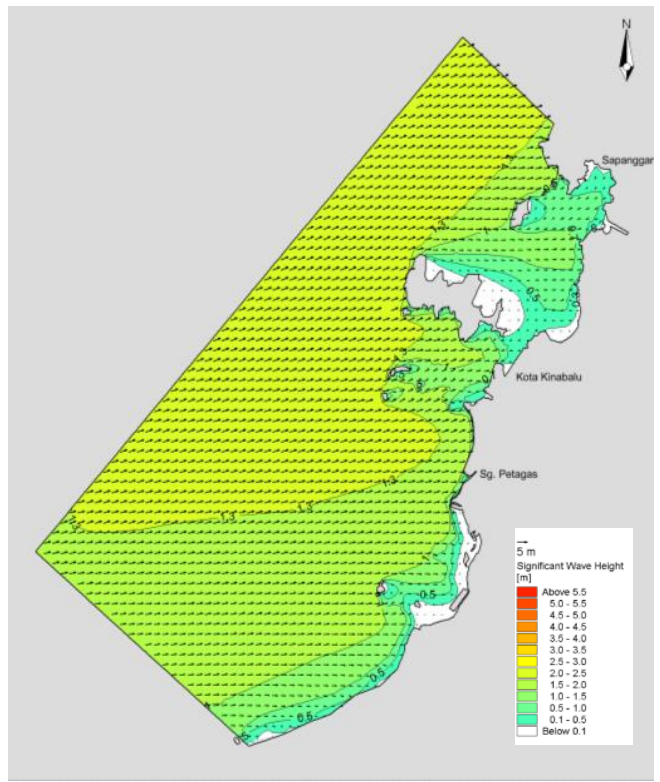

Figure 6 : (a) Overview of transformation of waves from offshore to nearshore for typical NE monsoon condition (b) Detailed view of the transformation of waves from offshore to near shore

for typical NE monsoon condition (c) Overview of transformation of waves from offshore to nearshore for typical SW monsoon condition (d) Detailed view of transformation of waves from offshore to nearshore for typical SW monsoon condition. 


\subsection{Hydrodynamics}

\subsubsection{Model Verification}

To ensure the accuracy of the simulated tidal currents within the model domain, the model was calibrated and verified using data obtained from tide gauges sited on the northwest coast of Sabah. During the calibration, the model parameters were adjusted within reasonable limits in an effort to match the model results with the observed water levels.

Figure 7 shows a comparison of the observed and predicted water levels for the Kota Kinabalu and Kuala Papar tidal stations, both of which lie in the vicinity of the river channel entrance. The predictions correspond accurately to the recorded data at these two points, capturing both the tidal amplitudes and the tidal phases. 
Predicted tidal elevation (Kota Kinabalu) [m]
Simulated tidal elevation

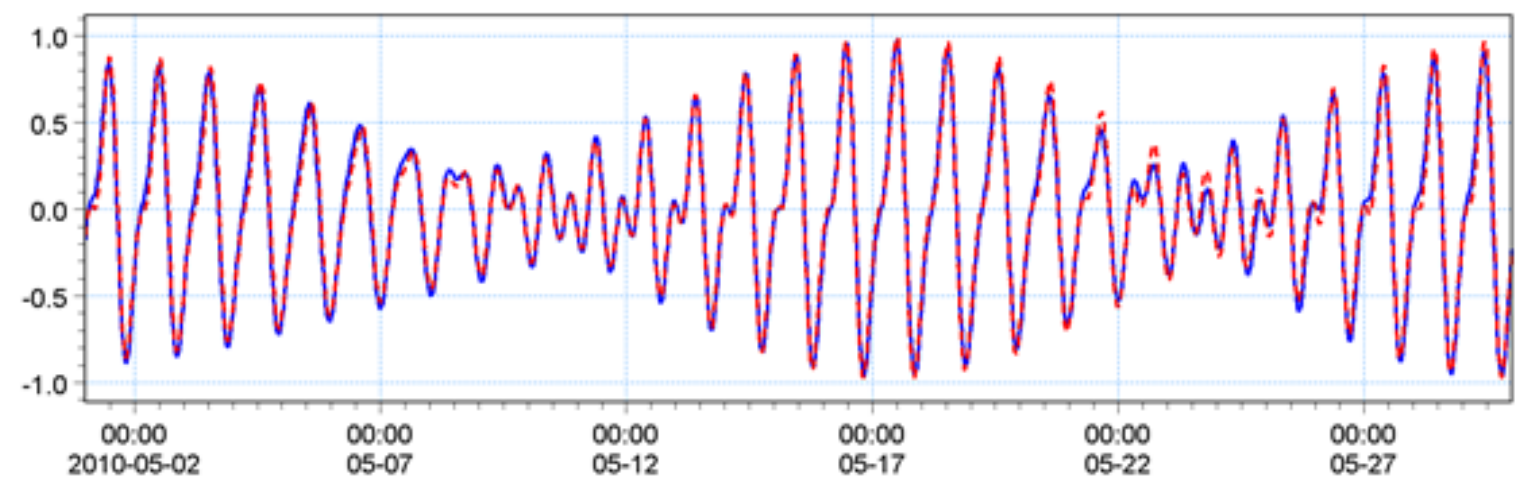

b Predicted tidal elevation (Kuala Papar) $[\mathrm{m}] \overline{\text { Simulated tidal elevation }}-\overline{\ldots-\ldots}$

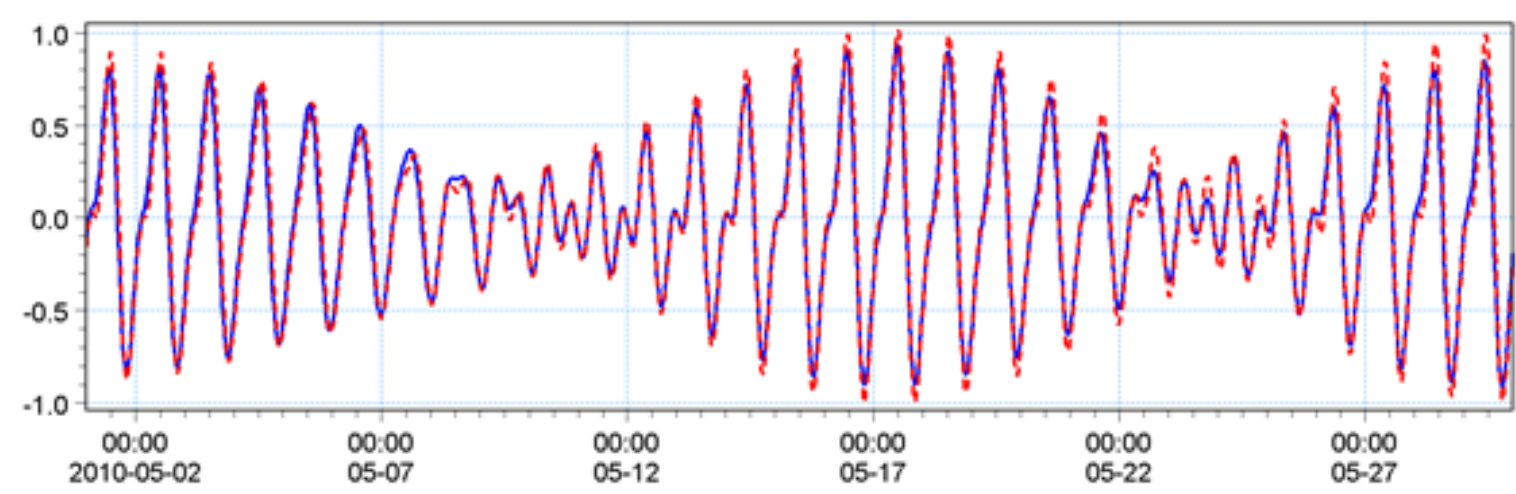

Figure 7 - Comparison of predicted and observed time series for the (a) Kota Kinabalu and Kuala (b) Papar tidal station.

In order to verify the results of the local model, water levels and currents were measured near the river channel entrance (seawards of the reclamation associated with the runway extension of Kota Kinabalu International Airport), as well as the areas upstream of it. Strong winds and heavy rain were reported during the period when the current measurement conducted, both of which affected the currents at the site.

River discharge and wind data were also obtained and included in the local model in addition to the data collected through the output from tidal variation. Measured and predicted water levels, current speeds and directions at locations seawards of the reclamation, and in the river itself, are compared in Figure 8 and Figure 9. 
For the seaward locations, the water levels show quite good agreement for both neap and spring tides. The measured current speeds are fairly low at both locations as shown in Figure 8 and Figure 9; with a strong influence of wind and little directionality due to the tide. For this reason we do not believe it is possible to reproduce the current conditions by merely using the tide and the river discharge. Hence, local wind data from Kota Kinabalu airport (hourly mean wind speed and direction) was applied, unfortunately with little success. The hourly mean wind speed was very low (around $2 \mathrm{~m} / \mathrm{s}$ for long periods), and weaker correlation was demonstrated between wind and current directions. In shallow water, the currents were mainly influenced by the river discharge, being governed by the narrow channels that direct the discharge over the tidal flat at the river channel entrance. 

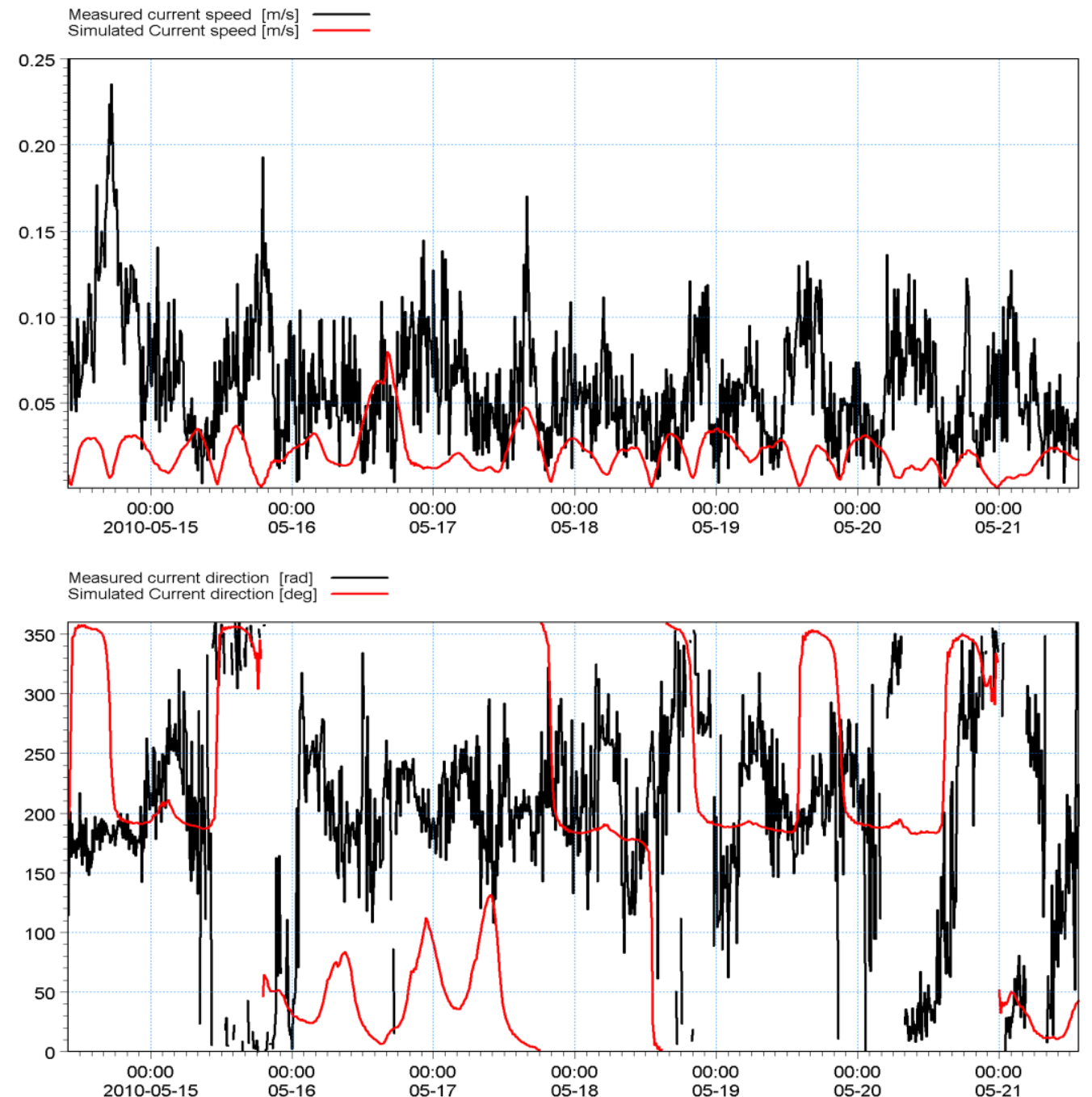

Measured water level $[\mathrm{m}]$
Simulated water level [m]

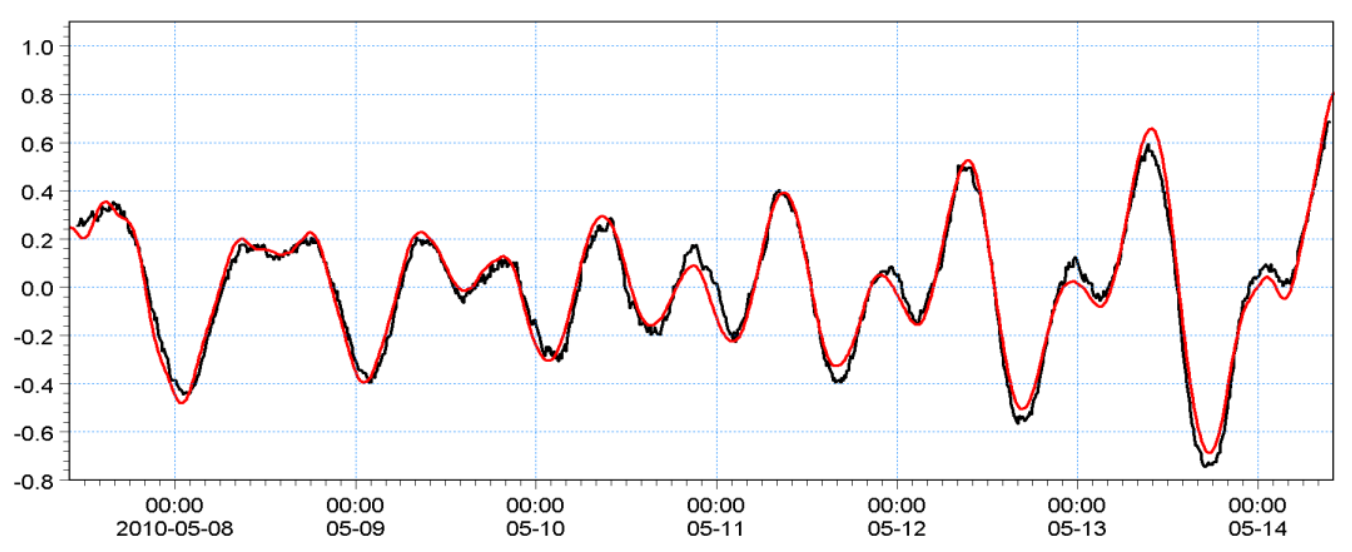

Figure 8 : Comparison of measured and predicted current for Acoustic Doppler Current Profiler ADCP 1 (deep water) 


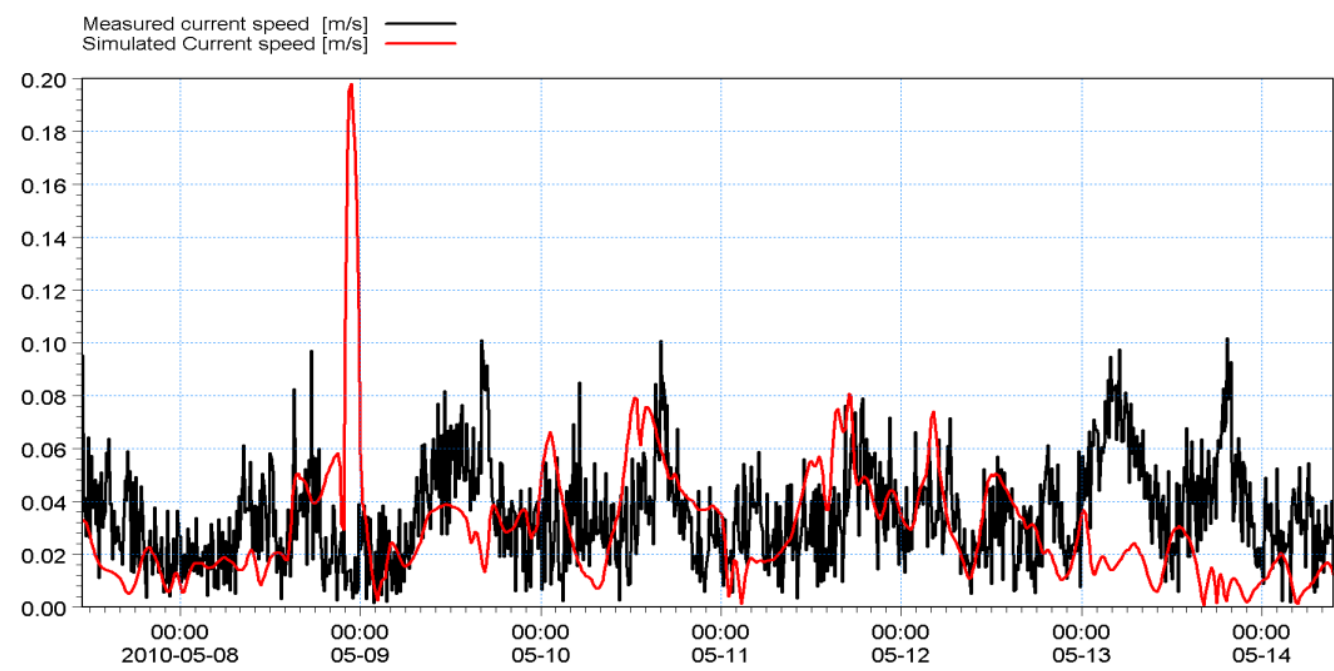

Measured current direction [rad]

Simulated Current direction [deg]

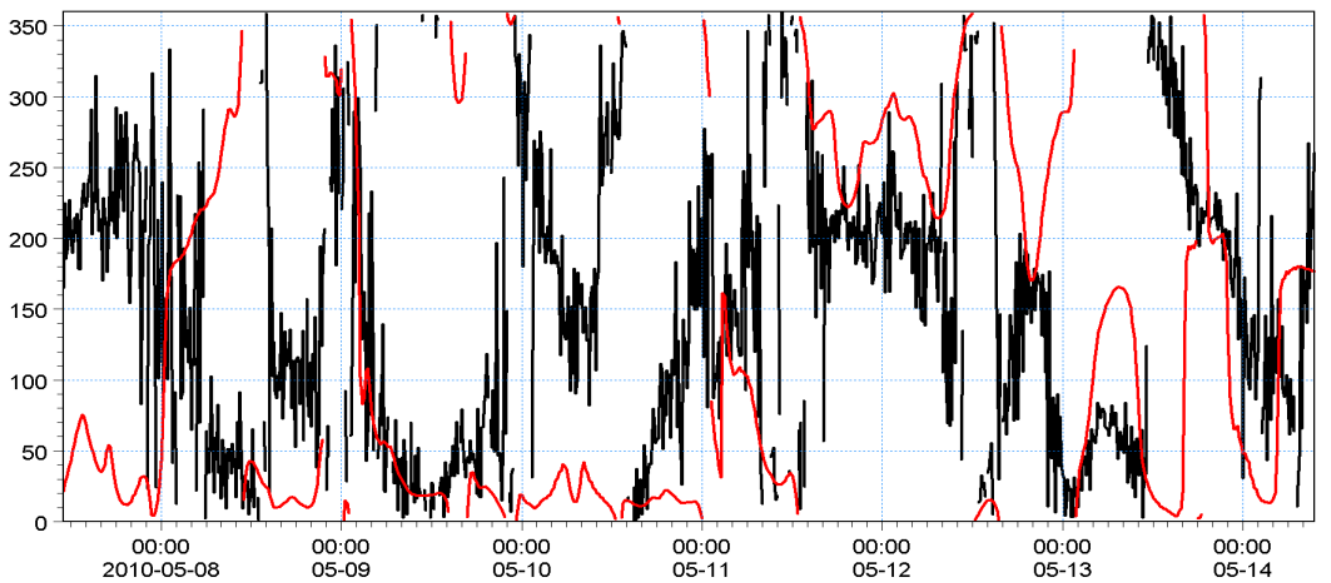

Measured water level $[\mathrm{m}]$
Simulated water level $[\mathrm{m}]$

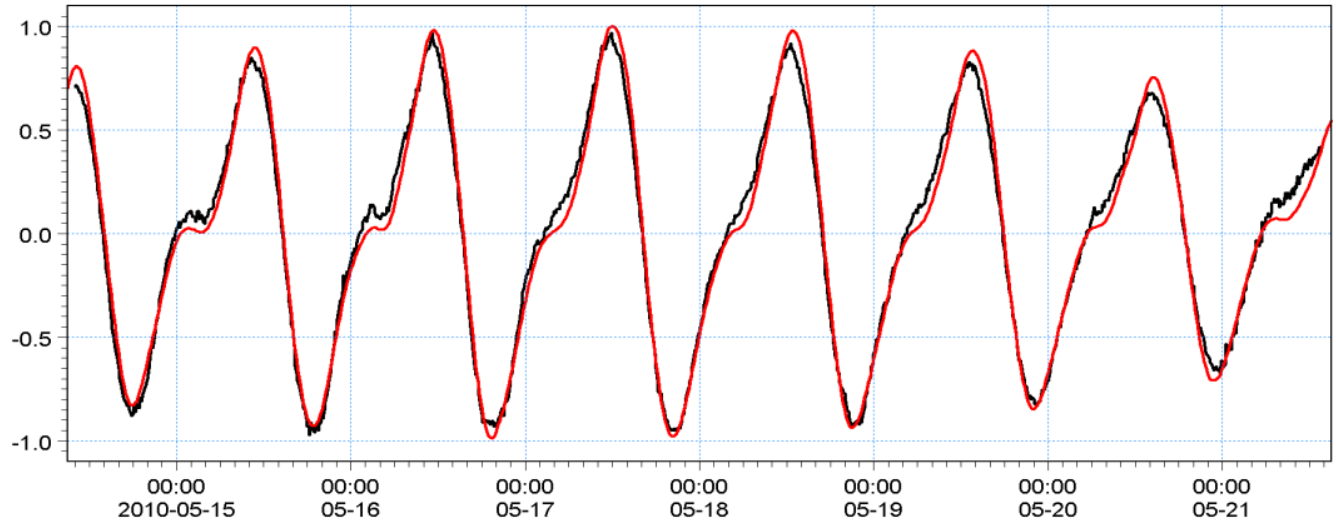

Figure 9 : Comparison of measured and predicted current at Acoustic Doppler Current ProfilerADCP 2 (shallow water). 
A comparison between the measured and predicted current speed in the river channel is shown in Figure 10. The model demonstrated well the water levels and current speeds, additionally by capturing the effect of a high discharge that followed a period of heavy rainfall on 02 August - 21:35. The measured current directions are not bidirectional (as may be expected in a tidal river); instead, significant cross-channel currents was observed. These may be ascribed to the helical flow conditions associated with the river bends near the measuring point, and the asymmetrical bathymetry of the shallow river. 

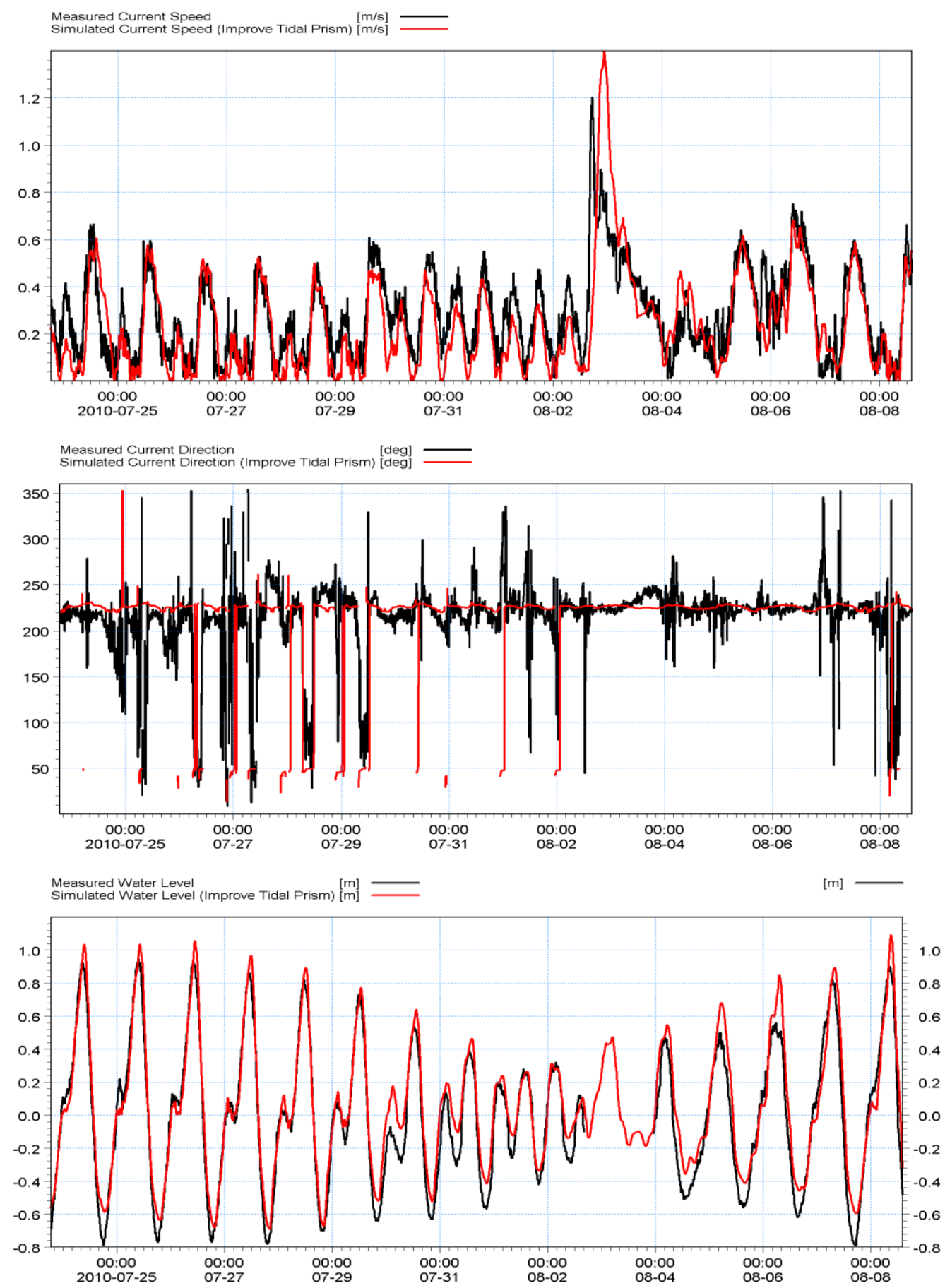

Figure 10 : Comparison of measured and predicted current and water level in the river 


\subsubsection{Existing conditions}

The instantaneous flood and ebb tide currents under different seasonal conditions are shown in Figure 11 and Figure 12, for the existing case and after the proposed improvement works. Comparing these figures allows an assessment to be made to improve effectiveness of the works for the different modelled conditions. 


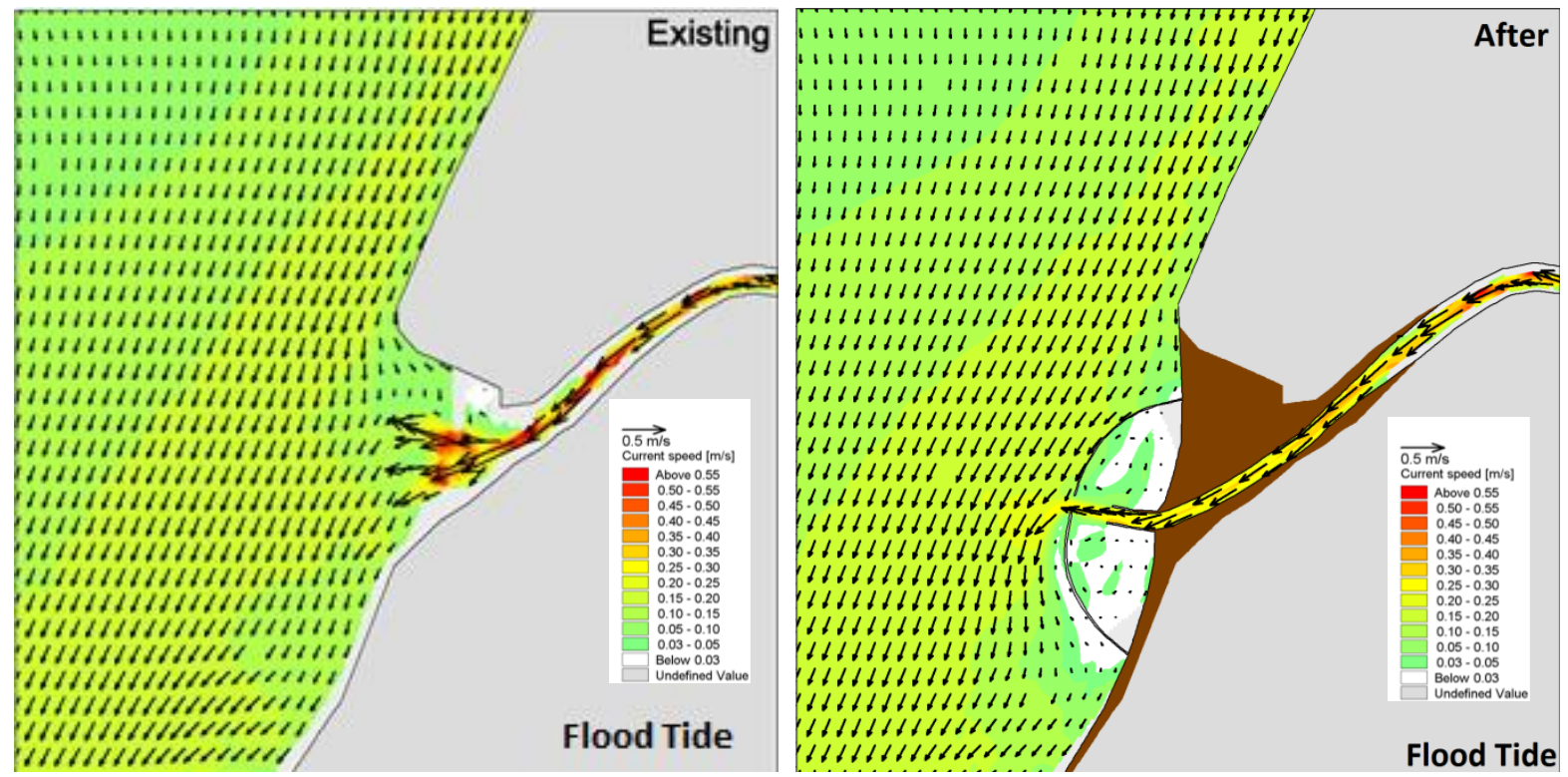

c

d

\begin{tabular}{|c|c|c|c|}
\hline 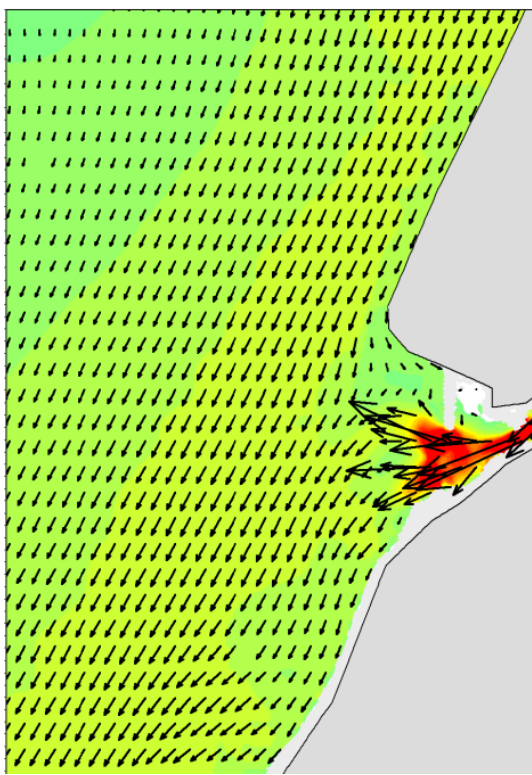 & 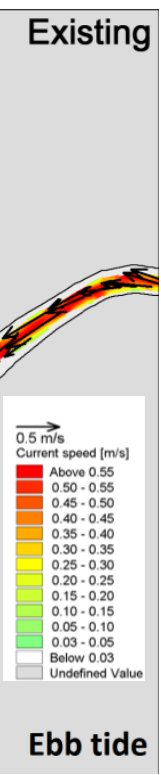 & 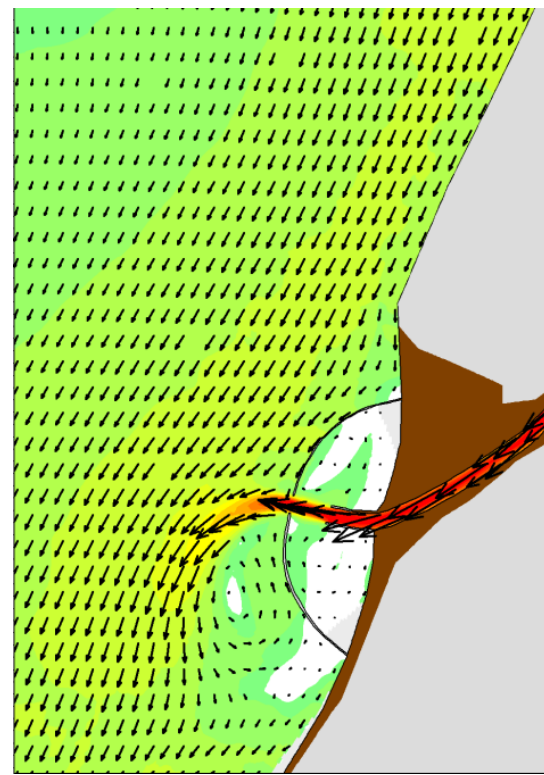 & 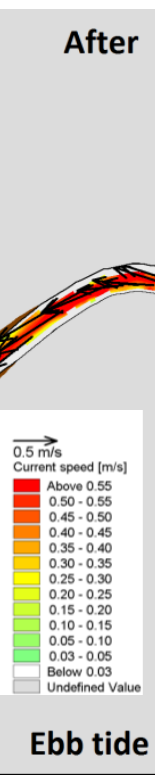 \\
\hline
\end{tabular}

Figure 11 : Current speed and direction for NE monsoon for (a) existing case during flood tide conditions (b) following improvement works during flood tide conditions (c) existing case during ebb tide (d) following improvement works during ebb tide. 


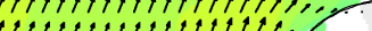

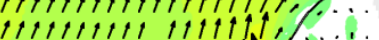

tोी

titttitttttti

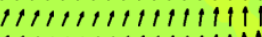

tit titt tीt tी

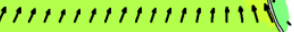

t1t $1+1+1+1+1111$

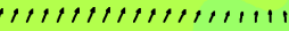

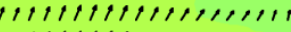

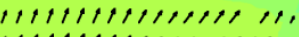

m tittitim

ורו

Flood tide

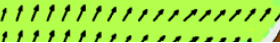

d

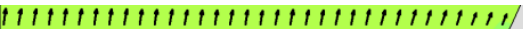

$t+t+t|t+t| t|t| t|t| t|t| t \mid t$

tीt tीt ttttttttttttttttt

tीtीtीt tीtttttttttttt,

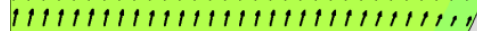

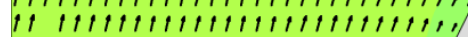

tीtीtीtीtीtीtीtीt

tीtीtीttीttीttीtी,

tीtीt tीt tीt tीt tीt

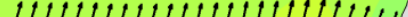

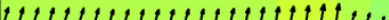

tilt

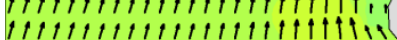

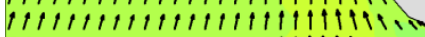

$t t t+t t t+t t t t t+t|t| t \mid$

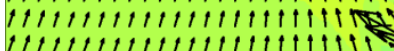

th 1 tी 1 tी 1 tी 1 tी 1 tी

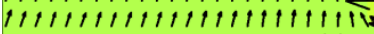

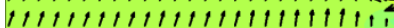

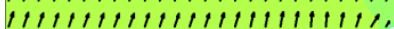

tो tो tो tो tोt tोt

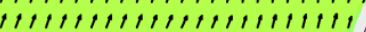

$t+1+1 t+1,1+1, t+1 t 1$

tो 1 tी

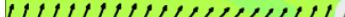

IIt

11

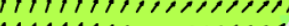

t

...

$\cdots$

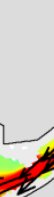

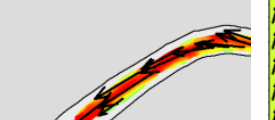

Existing

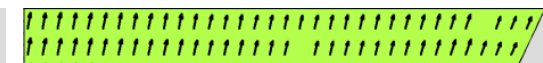
tी
tी $t$ tी $t$ tी $t$ tी
If

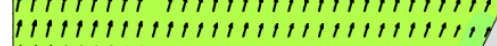
tी
tी
tी
tी tी

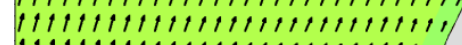
tी

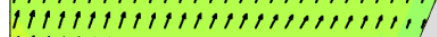

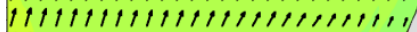

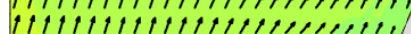
th tht

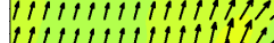

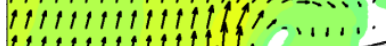

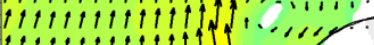
tt tt tीt tीt titffyt tो

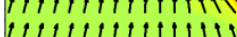
tी

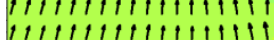

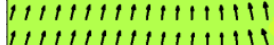
$t 1 t+1 t+1+1+1 t 1$ $t t t t t 1 t, t+1+1\}$ t $t$ tी $t$ t $11,1,1, t$ tो

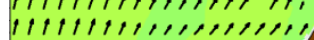

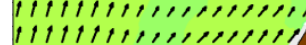
tithtititis

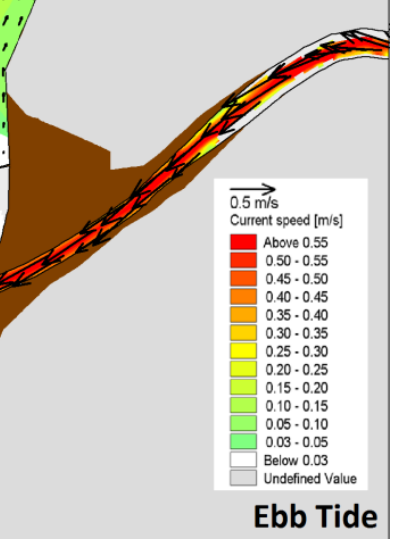

Figure 12 : Current speed and direction for SW monsoon for (a) existing case during flood tide conditions (b) following improvement works during flood tide conditions (c) existing case during ebb tide conditions (d) following improvement works during ebb tide conditions. 
The current direction is seawards, reflecting the direction of the monsoon, as shown in Figure 11 and Figure 12. The river current is high during ebb tide conditions (Figure $11 c, d$ and Figure $12 c, d)$ with a difference of about $50 \%$ in terms of flow velocity compared with flood tide conditions (Figure $11 a, b$ and Figure $12 a, b)$. The flow patterns in the vicinity of the proposed improvement works are generally smooth, with minimal differences between the two sets of figures in the immediate vicinity of the works, where eddies are generated downstream of the structures. The flow patterns in the trained channel, the breakwater basin and the channel entrance are found to be smooth, with limited transverse currents and merely weak eddy formations (Figure $11 b, d$ and Figure $12 b, d)$.

Eddies are easily formed in the basin during flood tide conditions; however the eddies are weak and not significant for navigation. The improvement works therefore provide an easy navigable access channel into the river. 


\subsection{Sedimentation}

The main sediment source is from Moyong catchment upstream. The changes in land use due to development has caused the increase in sediment to be washed into the channel and ultimately flushed downstream. This process tends to be worsened during monsoon seasons where rainfall intensity is high within the catchment as stated by (Mitchell 2013).

Numerical Two-dimensional mud transport simulations were carried out for the typical NE and SW monsoon periods in order to provide information on sedimentation, as shown in Figure 13.

NE monsoon conditions lead to a concentration of net deposition to the south of the river channel entrance, while SW monsoon conditions caused net deposition to the north. The configuration of the breakwaters demonstrates an effective means of directing the sediment into deeper waters. Beach is predicted to be accredited to the south of the breakwaters, while erosion is likely to occur downdrift, along the small stretch of coastline between the breakwater and the KKIA reclamation. Sediments are deposited inside the harbour basin as well.

Figure 13 delineates the changes of bed thickness for the NE and SW monsoon conditions respectively, as generated by the model. As illustrated in the figure, it demonstrated minimal or absent of net sediments deposition in the trained part of the river channel or at the channel exit, which appears to be well flushed. The sediments are deposited outside the training walls and breakwaters, resulting in the formation of a new flat. 
Following the management measures, sedimentation is predicted to take place in the lee zones within the harbour basin. The flow eddies generated on both sides of the access channel within the breakwater will flush away the sediment that enters through the breakwaters from the open sea and the river system towards the more protected parts of the basin, in which the transport capacity is low and the sediments can settle. The areas of sedimentation are mainly determined by the Northeast (NE) and Southwest (SW) monsoon. The sedimentation is strongly related to the current speed (refer to 
Existing condition). The net deposition appears to cover a wider area during the SW monsoon (Figure $13 c, d$ ) as the current and wind directions are uniform during this period.

a

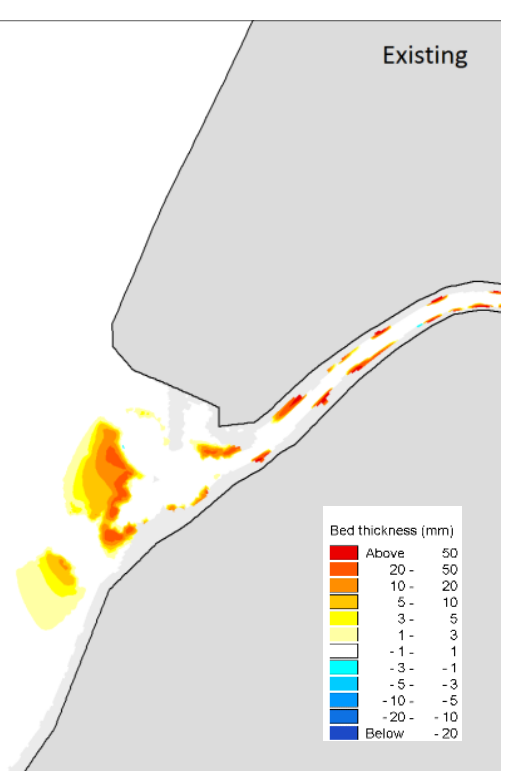

$\mathrm{c}$

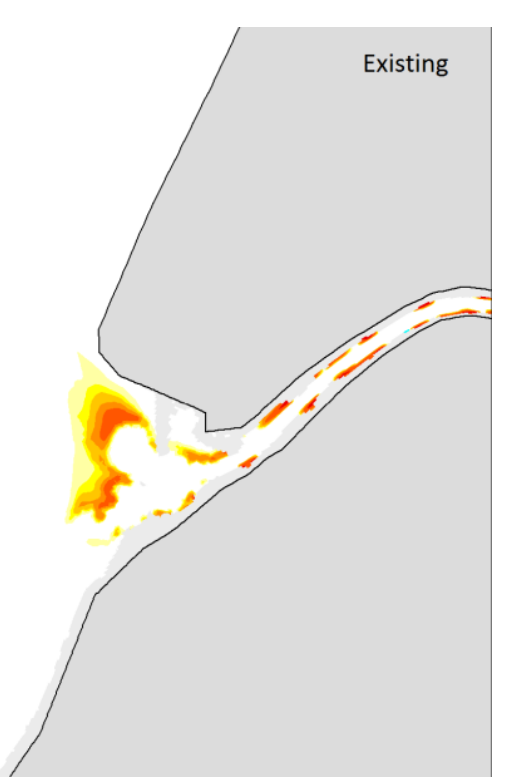

b

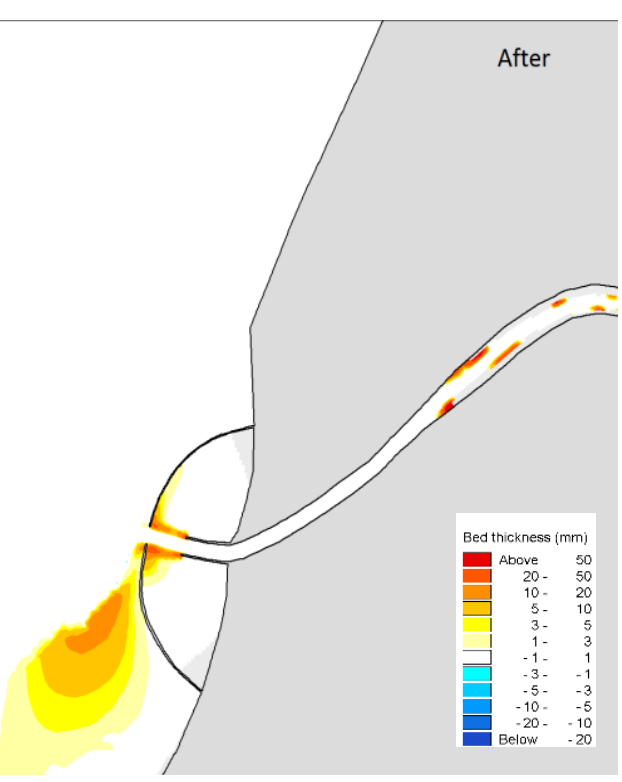

d

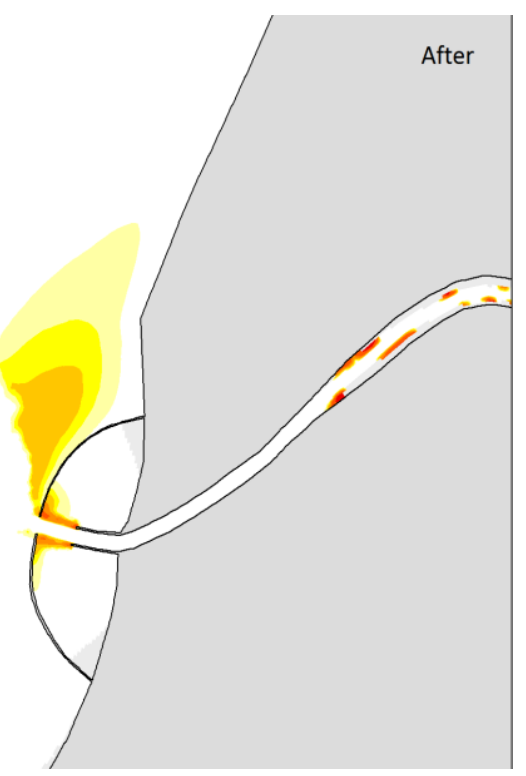

Figure 13 : Comparison of bed thickness changes (net deposition) during NE monsoon conditions for (a) existing case (b) following improvement works. Comparison of bed thickness changes (net deposition) during SW monsoon conditions for (c) existing case (d) following improvement works. In this monsoon condition, it shows the accuracy of the model by comparing to the satellite image as shown in Figure 14 


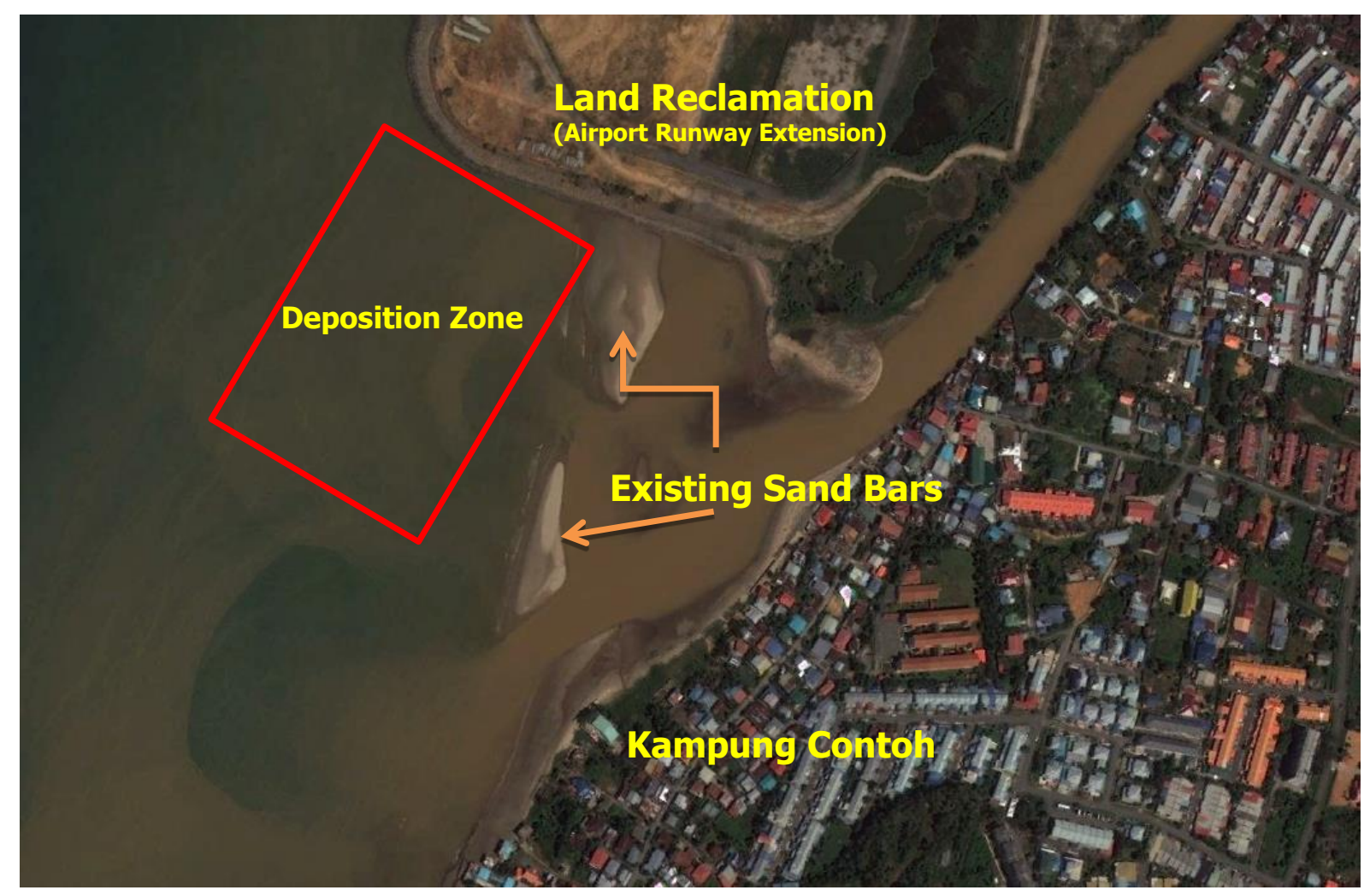

Figure 14 - Satellite image of current river channel entrance condition

Figure 14 shows the existing river channel entrance during South West monsoon period; the existing sand bars have formed since the land reclamation for the KKIA runway which extended to the north of the river channel entrance in the indicated location. By comparing the model results as shown in Figure 13 with the satellite image, the bed changes in the deposition zone reflects the bed thickness changes shown in the model in Figure 13c. 
The results show that sediments deposition mainly occur in the shallow river channel entrance for both monsoons transition, as well as on the tidal flat located at the south of the reclamation for the KKIA runway extension. This visual comparison provides confirmations in the patterns of sedimentation predicted by the model.

The management measure demonstrated in the outcome of this approach shows significant improvement in terms of flow capacity in the inter-annual climate variations in the monsoon. This constant opening of the river channel entrance will allow sufficient discharge and ultimately mitigate flooding upstream. The training channel that is dredged further out into the open sea will avoid sediment inland to be deposited at the entrance. With this, the constant navigability is available at the river channel entrance. The round shaped breakwaters will provide shelter for watercrafts and will seemingly create a bypass for northward sediment transport, this structure will be able to avoid sedimentation at the vicinity of the river channel entrance. Although the initial cost of this proposed management measure may be on the high side, the structure requires minimal maintenance compared to the currently frequent dredging required to maintain the river channel opening. This will result in overall cost savings. 


\section{Conclusions}

The modelling results from Sungai Petagas obtained in the present study indicate that the influence of river discharge, current, wind, waves and tides are important in determining the distribution and rate of sedimentation at the river channel entrance. The main conclusions of the present study are summarised as follows:

- The model set up is successful by using the demonstrated numerical modelling technique.

- The model accurately investigated the effect of monsoon seasons on the hydraulics and sediment dynamics aspects at the river channel entrance. The simulation is verified by site data collected and is well represented when compared to the satellite image taken.

- The well represented model will serve as an example for future establishment of numerical model of river channel entrance, which can serve as a numerical tool for solving similar river channel entrance problems especially in the west coast of Borneo.

- Good accuracy of the model enables assessment of the Petagas River entrance problem from obtaining the impacts of the proposed management works. 
- The proposed improvement works provide a well-defined and wider river channel that will allow the passage of watercrafts regardless of the state of the tide; and with an entrance located in deeper water, safety measure is reassured due to wave breaking along the shoreline.

- The training of the river channel results in increased current speeds, along with a more predictable and smoother flow and limited cross current, easing the problems of navigation through the river channel entrance.

- The proposed improvement works are predicted to lead to improved conveyance during high discharge events that could mitigate the effects of flooding upstream.

- The proposed channel will solve the sedimentation problems by increasing channel currents, thereby enabling flushing of sediment into deeper water.

Without any intervention, the river channel entrance is predicted to silt up and block altogether in the near future, causing flooding upstream and affecting the livelihood of the populations living in the rapidly developing Moyong catchment.

With this approach of effectively linking model components and assembling them to sufficiently represent a system as a whole is critical, which is demonstrated in this modelling approach where the coupled reductionist model successfully represent a sufficient range of real-world situation where waves and tidal variant is accurately 
simulated over the monsoon seasons. This shown by using variable mesh resolution throughout the model domain for efficient utilisation of computational cost. The result of wave generated as shown in section 4.1 successfully generated waves in offshore regional model then transferred to near shore local model between the monsoon seasons. The wave local model generated is then coupled with hydrodynamic model to produce tide and current patterns for the existing condition, the calibration and verification of the model is also done post outcome of this process to assess the accuracy of the model with the actual site condition as shown in section 4.2.

With the approach of integrated reduced complexity model, the model has successfully proven to be effective in simulating realistic emergent behaviours and topographic change over sufficient spatial and temporal scales. Where a sediment source is input into the estuary and coupled with the hydrodynamic model to simulate sedimentation in the river channel entrance between the monsoon seasons. Following that, the prediction of the river channel entrance with regards to the management measure is then assessed by coupling the proposed management scheme in section 4.3.

The numerical modelling approach used in accurately predicting this management scheme demonstrates a solution to meet the requirement of policy makers and can be adopted as as long term solution to similar local areas especially in the vicinity of river channel entrance discharging into South China Sea. Most importantly this paper demonstrates the sound development of seasonal influenced river channel entrance management strategy which requires sufficient prediction of coastal change at the mesoscale. This approach also demonstrates the major importance to simulate coastal environment as an overall system and to appreciate the crucial interactions that occur 
between the open coast, catchment and the shallow vicinity of the river channel entrance. With the strength of each model types currently available, a coupled multimodel framework is the key in serving as an example for future establishment of numerical model of river channel entrance, which can serve as a numerical modelling approach for solving similar dynamic river channel entrance problems especially in the east coast of Borneo.

While this paper contains promising results in terms of integrating multiple modelling approaches, there are many challenges for further research. For example, detailed study of the catchment is crucial as future urbanisation is predicted to cause increased discharges. As a consequence of such development, the sediment properties may change leading to different sedimentary behaviour. However, a proper prediction for the future of a constantly evolving river due to ongoing development remains a challenging subject for researchers. 


\section{Acknowledgements}

The authors are grateful to the 'Department of Irrigation and Drainage Malaysia' for their technical support and providing data for this research, to Jurukur Vitus Tan and Associates for survey and field data, to the Department of Survey and Mapping (JUPEM) for supplying the tidal data sets, and to Kota Kinabalu International Airport (KKIA) for the wind data sets. DHI Water \& Environment provided technical advice and assistance with modelling. 


\section{References}

Aackermann, Peter Edward, Peter Juhler Denesen Pedersen, Allan Peter EngsingKarup, Thomas Clausen, and Jesper Grooss. 2012. Development of a GPUACCELERATED MIKE 21 Solver for Water Wave Dynamics. Technical University of Denmark, DTU Informatics.

Abdullah, Mohd. Kamal. 2012. Malaysians Must Know the Truth. 24 June. http://malaysiansmustknowthetruth.blogspot.com/2012/06/petagas-river-mouth-tooshallow.html.

Abdullah, Sharifah Mastura Syed. 1992. The Coastal Zone in Malaysia: Processes, Issues and Management Plan. Kuala Lumpur: Government of Malaysia.

Amos, C. L. 1995. "Siliciclastic Tidal Flats." In Developments in Sedimentology, 273306. Amsterdam: Elsevier.

Amoudry, Laurent. 2008. A Review on Coastal Sediment Transport Modelling. Natural Environment Research Council.

Bonaldo, Davide, Alvise Benetazzo, Mauro Sclavo, and Sandro Carniel. 2015. "Modelling wave-driven sediment transport in a changing climate: a case study for northern Adriatic Sea (Italy)." Regional Environmental Change 45-55.

Chen, Xin, Yong Li, Xiaojing Niu, Daoyi Chen, Ming Li, and Xiping Yu. 2011. "A general two-phase turbulent flow model applied to the study of sediment transport in open channels." International Journal of Multiphase Flow 37: 1099 - 1108.

Chiang, Yun-Chih, and Sung-Shang Hsiao. 2011. Coastal Morphological Modeling, Sediment Transport in Aquatic Environments. In Tech.

DBKK. 2011. KK Local plan (KKLP) 2020. Kota Kinabalu: Kota Kinabalu City Hall.

Deloffre, J., R. Lafite, P. Lesueur, R. Verney, S. Lesourd, A. Cuvilliez, and J. Taylor. 2006. "Controlling factors of rhythmic sedimentation processes on an intertidal estuarine mudflat - Role of the turbidity maximum in the macrotidal Seine estuary, France." Marine Geology 151-164.

Department of Irrigation and Drainage. 2011. "Master Plan Study for Moyong River Basin." Kota Kinabalu.

Department of Irrigation and Drainage, Malaysia. 2001. Guidelines for Preparation of Coastal Engineering Hydraulic Study And Impact Evaluation.

DHI Water \& Environment b. 2007. MIKE 21 FLOW MODEL - User Guide. Hørsholm: DHI.

DHI Water \& Environment c. 2007. MIKE 21 \& MIKE 3 FLow Model FM - Hydrodynamic Module. Hørsholm: DHI Water \& Environment. 
DHI Water \& Environment d. 2009. MIKE 21 FLOW MODEL - Hydrodynamic Module Scientific Documentation. Hørsholm: DHI Water \& Environment.

DHI Water \& Environment. 2007a. MIKE 21 Wave Modelling - MIKE 21 SW - Spectral Waves FM. Hørsholm: DHI.

DHI Water and Environment. 2007. MIKE 21 FM - Mud Transport Module. Horsholm: DHI Water \& Environment.

DID. 2011. "Master Plan Study for Moyong River Basin." Kota Kinabalu.

Dinehart, R. L., and R. Burau J. 2005. "Repeated surveys by acoustic Doppler current profiler for flow and sediment dynamics in a tidal river." Journal of Hydrology $1-21$.

Engelund, Frank, and Eggert Hansen. 1967. "A Monograph on Sediment Transport in Alluvial Streams, Teknisk Vorlag, Copenhagen."

e-SABAHDAILY. 2013. Flood problems remain unsolved, Sabahan always soaked in deep flood water. - See more at: http://e-sabahdaily.com/news/floodproblems-remain-unsolved-sabahan-always-soaked-in-deep-flood-

water/\#sthash.ZzXMSHrT.dpuf. 4 January. http://esabahdaily.com/news/flood-problems-remain-unsolved-sabahan-alwayssoaked-in-deep-flood-water/.

French, J. R., and H. Burningham. 2009. "Coastal geomorphology: trends and challenges." Prog. Phys. Geor. 33 117-129.

French, Jon, Helene Burningham, Gillian Thornhill, Richard Whitehouse, and Robert J. Nicholls. 2016. "Conceptualising and mapping coupled estuary, coast and inner shelf sediment systems." Geomorphology 17-35.

Frienrichs, C.T. 2014. "Tidal Flat Morphodynamics: A Synthesis." In Treatise on Estuarine and Coastal Science, 137-170. Virginia.

Galloway, William E. 1975. "Process Framework for Describing the Morphologic and Stratigraphic Evolution of Deltaic Depositional Systems." Deltas Models for Exploration 87 - 98.

GROW. n.d. GROW. Oceanweather Inc. Accessed 23 November, 2012. http://www.oceanweather.com/metocean/grow/index.html.

Guerrero, M., N. Rüther, R. Archetti, and .. 2014. "Comparison under controlled conditions between multi-frequency." Flow Measurement and Instrumentation 73-82.

Harding, S. F., M. C. Richmond, P. Romero. Gomez, and J. A. Serkowski. 2016. "Effects of non-homogeneous flow on ADCP data processing in a hydroturbine forebay." Flow Measurement and Instrumentation.

Hinrichsen, Don. 1998. Coastal population and altered land cover in coastal zones. Washington D.C: Island Press. 
Husain, Mohd Lokman, Rosnan Yaakob, and Shahbudin Saad. 1993. "Beach Erosion Variabiltiy during a Northeast Monsoon: The Kuala Setiu Coastline, Terengganu, Malaysia." Pertanika Journal of Sci. \& Technology. 3 (2): 337-348.

ICZM Task Force. 1998. "Climate." In Sabah Coastal Zone Profile. Kota Kinabalu.

Jayappa, K. S., and A.C. Narayana. 2009. Coastal Environments Problems and Perspectives. New Delhi: I. K. International.

Kim, Dongsu, and Marian Mustle. 2012. "Multi-dimensional representation of river hydrodynamics using ADCP data Processiong Software." Environmental Modelling and Software 158-166.

Kocar, Benjamin D., and Fendorf Scott. 2012. "Arsenic Release and Transport in Sediments of the Mekong Delta." Terrapub 117-124.

Krone, R. B. 1962. Flume Studies of the Transport of Sediment in Estuarial Processes. Berkely: University of California .

Lesourd, S., P. Lesuer, J. C Brun-Cottan, S. Garnaud, and N. Poupinet. 2003. "Seasonal variations in the characteristics of superficial sediments in a macrotidal estuary (the Seine inlet, France)." Estuarine, Coastal and Shelf Science 3-16.

Liang, M., V.R. Voller, C. Paolo, and . 2015. "A reduced-complexity model for river delta formation - Part 1: Modeling deltas with channel dynamics." Earth Surface Dynamics, 28 Januaray: 67-86.

Lisitzin, Eugine. 1974. Sea-level changes. Amesterdam: Elsevier.

Malaysian Metrological Department. 2010. Malaysian Tide Table Volume 2.

Mangor, Karsten. 2007. VLAAMS INSTITUUT VOOR DE ZEE. VLAAMS INSTITUUT VOOR DE ZEE. 24 October. Accessed 23 October, 2012. http://www.vliz.be/wiki/Wave_climate_classification_according_to_wind_clima te.

Martins Silva, Lucas Filipe, Andreas Öchsner, and Robert Adams. 2011. Handbook of Adhesion Technology. Springer.

Mashriqui, Hassan Shahid. 2003. "HYDRODYNAMIC AND SEDIMENT TRANSPORT MODELING OF DELTAIC SEDIMENT PROCESSES." Louisiana.

Mitchell, Steven. 2013. "Turbidity maxima in four macrotidal estuaries." Ocean and Coastal Management 62-69.

Naess, A., M. ASCE, and P. H. Clausen. 2000. "THE PEAKS OVER THRESHOLD METHOD AND BOOTSTRAPPING FOR ESTIMATING LONG RETURN PERIOD DESIGN VALUES." ASCE Specialty Conference on Probabilistic Mechanics and Structural Reliability. ASCE.

Nelson, Steven M., Francisco Zamora Arroyo, Jorge Ramírez Hernández, and Edith Santiago Serrano. 2013. "Geomorphology of a Recurring Tidal Sandbar in the 
estuary of the Colorado River, Mexico: Implications for restoration." Ecological Engineering 121-133.

Nichollas, R. J., A. Brandbury, H. Burningham, J. Dix., M. Ellis, J. French, J.W. Hall, et al. 2012. "Integrating Coastal Sediment Systmes." iCOASST - Proceedings of the International Conference on Coastal Engineering. Spain: Santander. 15.

Nylen, Linda, and Ebba Ramel. 2011. The effects of inlet sedimentation on water exchange in Maha Oya Estuary, Sri Lanka. Lund: Lund University.

Orton, G. J., and H. G. Reading. 2006. "Variability of deltaic processes in terms of sediment supply, with particular emphasis on grain size." Sedimentology Vol 40 475-512.

Outskirtoutrich.org. n.d. Monson Mood Swings in Malaysia. Accessed 20 April, 2012. http://outskirtoutreach.org/monsoon-malaysia-season-east-west-perhentianredang-tioman-pangkor-langkawi-borneo/.

Pruszak, Zbigniew, and Marek Szmytkiewicz. 2005. "Hydrology and morphology of two river mouth regions." Oceanlogia 365 - 385.

Razak, Z., A. Zuhairi, S. Shahbudin, and Y. Rosnan. 2012. "2-Dimensional Hydrodynamic Patterns of Pahang River Estuary, Pahang, Malaysia during Northeast and Southwest Monsoon." UMT 11th International Annual Symposium on Sustainability Science and Management. Terengganu.

Robakiewicz, Małgorzata. 2010. "Vistula River Mouth - History and Recent Problems." Gdansk.

Roy, P. D., M. Caballero, S. Lozano, O. Morton, R. Lozano, M. P. Jonathan, J. L. Sanchez, and M. C. Macias. 2012. "Provenance of sediments deposited at paleolake San Felipe, western Sonora Desert: Implications to regimes of summer and winter precipitation during last $50 \mathrm{cal}$ kyr BP." Journal of Arid Environments (Journal of Arid Environments) 47-58.

Sabahkini.net. 2010. Sabahkini.net. Sabahkini.net. 13 May. Accessed 07 Oct, 2012. http://sabahkini.net/index.php?option=com_content\&view=article\&id=4015:p erennial-flood-in-kg-kibabaig\&catid=35:berita-sabah\&Itemid $=27$.

Samaras, Achilleas G., and Christopher G. Koutitas. 2014. "The impact of watershed management on coastal morphology: A case study using an integrated approach and numerical modeling." Geomorphology 52-63.

Santini, Monia, and Arianna di Paola. 2015. "Changes in the world rivers' discharge projected from an updated high resolution dataset of current and future climate zones." Journal of Hydrology 768-780.

Schmitt, Klaus, and Thorsten Albers. 2014. "Area Coastal Protection and the Use of Bamboo Breakwaters in the Mekong Delta." In Coastal Disasters and Climate Change in Vietnam, by Nguyen Danh Thao, Hiroshi Takagi and Miguel Esteban, 107-132. Elsevier. 
Soomere, Tarmo, Andres Kask, Juri Kask, and Healy Terry. 2008. "Modelling of wave climate and sediment transport patterns at a tideless embayed beach, Pirita Beach, Estonia." Journal of Marine Systems (Special Issue : Proceedings of the Baltic Sea Science Congress ): 133-146.

Stanley, D. J., and A. G. Warne. 1994. "Worldwide initiation of Holocene marine deltas by deceleration of sea-level rise." Science 265: 228-231.

Stark, Jeroen, Yves Plancke, Stefaan Ides, Patrick Meire, and Stijn Temmerman. 2016. "Coastal flood protection by a combined nature-based and engineering approach: Modelling the effects of march geometry and surrounding dikes." Estuarine, Coastal and Shelf Science 34-45.

United Nations. 1969. Mekong River Delta Study. Paris: United Nations Educational, Science and Cultutral Organisation.

Valsamidis, Antonios, Grzegorz Różyński , Dominic E. Reeve, and . 2013. "Data-driven analysis of medium-term wave-seabed interactions at a non-tidal beach with multiple bars." Marine Geology 144-154.

Veerbeek, William. 2007. Ranking of the world's cities most exposed to coastal flooding today and in the future. OECD.

Walkden, M. J. A., M. E. Dickson, J. W. Hall, and . 2015. "Simulating the shore and cliffs of North Norfolk." In Broad Scale Coastal Simulation: New Techniques to Understand and Manage Shorelines in the Third Millennium, by Robert J. Nicholls, Richard J. Dawson and Sophie A. Day (née Nicholson-Cole), 349. Dordrecht: Springer.

Walkden, M. J., and J. W. Hall. 2011. "A Mesoscale Predictive Model of the Evolution and Management of a Soft-Rock Coast." Journal of Coastal Research 529-543.

Wang, Yu Hai, Li Qun Tang, Chong Hao Wang, Chun Jing Liu, and Zhan Di Dong. 2014. "Combined effects of channel dredging, land reclamation and long-range jetties upon the long-term evolution of channel-shoal system in Qinzhou bay, SW China." Ocean Engineering 340-349.

Wilcock, Peter R., and Stephen T. Kenworthy. 2002. "A two-fraction model for the transport of sand/gravel mixtures." WATER RESOURCES RESEARCH 38 (10 ).

Winnesota Rural Water Association. n.d. Sedimentation. Accessed 2012 November, 15.

Wong, P. P., I. J. Losada, J. P. Gattuso, J. Hinkel, A. Khattabi, K. L. McInnes, Y. Saito, and A. Sallenger. 2014. Coastal systems and low-lying areas. Fifth Assessment Report, United Kingdom and New York, NY, USA: Climate Change 2014: Impacts, Adaptation, and Vulnerability. Part A: Global and Sectoral Aspects. Contribution of Working Group II to the Fifth Assessment Report of the Intergovernmental Panel on Climate Change, 361-409. 
Woodroffe, C. D., R.J. Nicholls, Y Saito, Z Chen, and S Goodbred. 2006. "Lanscape variability and the response of Asian megadeltas to environmental change." Global Change and Integrated Coastal Management 277-314.

Woodroffe, Colin D., and Colin V. Murray-Wallace. 2012. "Sea-level rise and coastal change: the past as a guide to the future." Quaternary Science Reviews 4-11.

Wright, L. D. 1977. "Sediment transport and deposition at river mouths." Geol. Soc. Am. Bull., Vol 88 857-868.

Wright, L. D., and J. M. Coleman. 1972. "River Delta Morphology: Wave Climate and the Role of the Subaqueous Proffile." Science Vol $176282-284$.

Wright, L. D., and J. M. Coleman. 1973. "Variations in Morphology of Major River Deltas as Functions of Ocean Wave and River Discharge Regimes." AAPG Bulletin, Vol 57370 - 398.

Xue, Zuo, Ruoying He, J.Paul Liu, and John C. Warner. 2012. "Modeling transport and deposition of the Mekong River sediment." Continental Shelf Research 37: 6678.

Zbigniew, Pruszak, Ninh Van Pham, Szmytkiewicz Marek, Nguyen Manh Hung, and Ostrowski Rafał. 2005. "Hydrology and morphology of two rivermouth regions." Oceanlogica 47 (3): 365-385.

Zhou, Zeng, Giovanni Coco, Mick van der Wegen, Zheng Gong, Changkuan Zhang, and Ian Towned. 2015. "Modeling sorting dynamics of cohesive and noncohesive sediments on intertidal flats under the effect of tides and wind waves." Continental Shelf Research 76-91. 